\title{
42. PALEOMAGNETISM OF SEDIMENTS FROM DEEP SEA DRILLING PROJECT LEG 71
}

\author{
J. C. Salloway, Department of Geophysics, University of Edinburgh, Edinburgh EH9 3JZ, United Kingdom
}

\begin{abstract}
Paleomagnetic results are described from Site 511 on the Falkland Plateau and Sites 513 and 514 in the Southeast Argentine Basin. At Site 511 a magnetostratigraphy is constructed that can be compared with the major characteristics of the established Cretaceous magnetostratigraphy. At Site 513 a fairly complete uppermost Miocene magnetostratigraphy is presented, covering the interval 10 to $5 \mathrm{Ma}$. Hydraulic piston coring has led to the recovery of an almost complete magnetic record for the past $4 \mathrm{~m}$.y. from Site 514. All the major magnetic intervals are recognized, except for two that are absent because of a single unconformity. High sedimentation rate has permitted the study of polarity transitions, which appear to be nondipolar in nature.
\end{abstract}

\section{INTRODUCTION}

Paleomagnetic measurements were carried out on sediments recovered during Leg 71 of the Deep Sea Drilling Project. These consisted of Cretaceous to Quaternary sediments from the Falkland Plateau (Sites 511 and 512) and Oligocene to Quaternary sediments from the western flank of the Mid-Atlantic Ridge (Sites 513 and 514, see Fig. 1). The sediments were cored using both the rotary drill and the hydraulic piston method. Hydraulic piston coring, which was used at Sites 512 and 514, allows recovery of comparatively undisturbed sediment, in which relative orientation can be maintained. This should permit comparison of declination as well as inclination, so that both can be used to determine polarity.

\section{SAMPLING AND MEASUREMENT}

Paleomagnetic samples were taken using plastic cylinders $2.5 \mathrm{~cm}$ in diameter and approximately $2.5 \mathrm{~cm}$ in length and plastic boxes which approximate to $2-\mathrm{cm}$ cubes. These were pushed into undisturbed parts of the core, oriented by a notch which pointed upward, along the long axis of the core. The ends of the cylinders were sealed with adhesive tape. In the more lithified sediments toward the bottom of Site 511, a diamond-tipped drill was used to retrieve $2.5-\mathrm{cm}$ diameter minicores, which were trimmed to a length of about $2.5 \mathrm{~cm}$. The "black shales" of Site 511 tended to part along the thinly spaced bedding planes, so samples from this rock type were carved by knife into 2 -cm cubes. To preserve orientation in these cases, we inscribed an arrow pointing up the core on the sediment before sampling. The majority of the sampling was carried out on board Glomar Challenger. Additional samples, mainly from Site 513, were collected from the Lamont-Doherty Core Repository, 11 months after the end of the cruise.

Natural remanent magnetization (NRM) of the shipboard samples from Sites 511, 512, and 513 and half of the samples from Site 514 were measured on Glomar Challenger, using a Digico spinner magnetometer. Measurement of all the samples from Site 514 was carried out by a similar instrument at the University of Edinburgh. Further measurements, including all samples collected postcruise, were performed on a cryogenic magnetometer, initially at the University of Leeds and later at the University of Southampton. On board Glomar Challenger measurements were integrated over up to $2^{9}$ spins (depending on intensity). At $2^{9}$ spins the instrument noise averaged $0.066 \mu \mathrm{G}$. Shore-based results from Edinburgh are the average of at least two complete mea-

\footnotetext{
${ }^{1}$ Ludwig, W. J., Krasheninnikov, v. A., et al. Init. Repts. DSDP, 71: Washington (U.S. Govt. Printing Office).
}

surements, using integration over $2^{7}$ spins (average instrument noise $=0.056 \mu \mathrm{G}$ ). Instrument noise on the cryogenic magnetometer averaged $0.028 \mu \mathrm{G}$ over the period of measurement.

The samples from Sites 511 and 513 with stronger intensity were demagnetized on board Glomar Challenger with a Schonstedt alternating field demagnetizer. Additional samples from all four sites were demagnetized in Edinburgh. In both cases the three axes method was used, by which samples are demagnetized at the peak field along three mutually perpendicular axes, then demagnetized at half the peak field, with the previous orientation reversed with respect to the axis of the coils of the demagnetizer. It is assumed that there is a linear range of coercivities, so that any anhysteric remanent magnetization (ARM) that may develop will be cancelled out by the half-field demagnetization. Gyroremanent magnetizations (GRM) may develop if the sample exhibits anistrophy of magnetic susceptibility (Stephenson, 1980b). Investigations carried out on the equipment in Edinburgh showed that the rotational remanent magnetization (Wilson and Lomax, 1972; Stephenson, 1980a) produced by spinning sediments in an alternating field of $600 \mathrm{Oe}$ is greater than the ARM produced by 3 axes demagnetization at the same field. Demagnetization of the samples with lower intensities was carried out at Southampton so that their remanence could be measured using a cryogenic magnetometer. During demagnetization, samples were rotated about a single axis; direction of rotation was reversed after each complete turn so RRM would cancel out.

Small differences were noticed between shipboard and shore-based results. When these were the result of a small secondary component acquired after shipboard measurement, demagnetization at low fields or storage in zero field for sufficient length of time removed the anomalous component. Occasionally demagnetization led to a stable end point different from that measured shipboard. In such cases the remanence was measured on a cryogenic magnetometer and the land-based result probably reflects its greater accuracy.

The conventional rotary drilling method usually used on Glomar Challenger does not allow the preservation of relative orientation among cores. In fact, parts of the core often split and rotate relative to each other (a phenomenon known as "disking"). For these reasons it has not previously been possible to use declination to determine the polarity of sediments. With the advent of the hydraulic piston core it was hoped that the relative orientation of each core could be calculated. As noted in the site chapter for Site 512, a number of problems were encountered in measuring piston-cored sediment. The samples taken from piston-cored sediment show values of declination which are consistent with inclination within a single core-that is, they are constant corresponding to constant inclination and change through about $180^{\circ}$ corresponding to reversals of inclination. Thus it is possible to correct the declination values by rotating each core to give a mean value of $0^{\circ}$.

Low field susceptibility of samples from Sites 511,512 , and 513 was measured on a Digico susceptibility bridge at the University of Edinburgh. Susceptibility measurements and measurements of magnetic mineral content on samples from Site 514 were carried out by Bloemendal (this volume). 


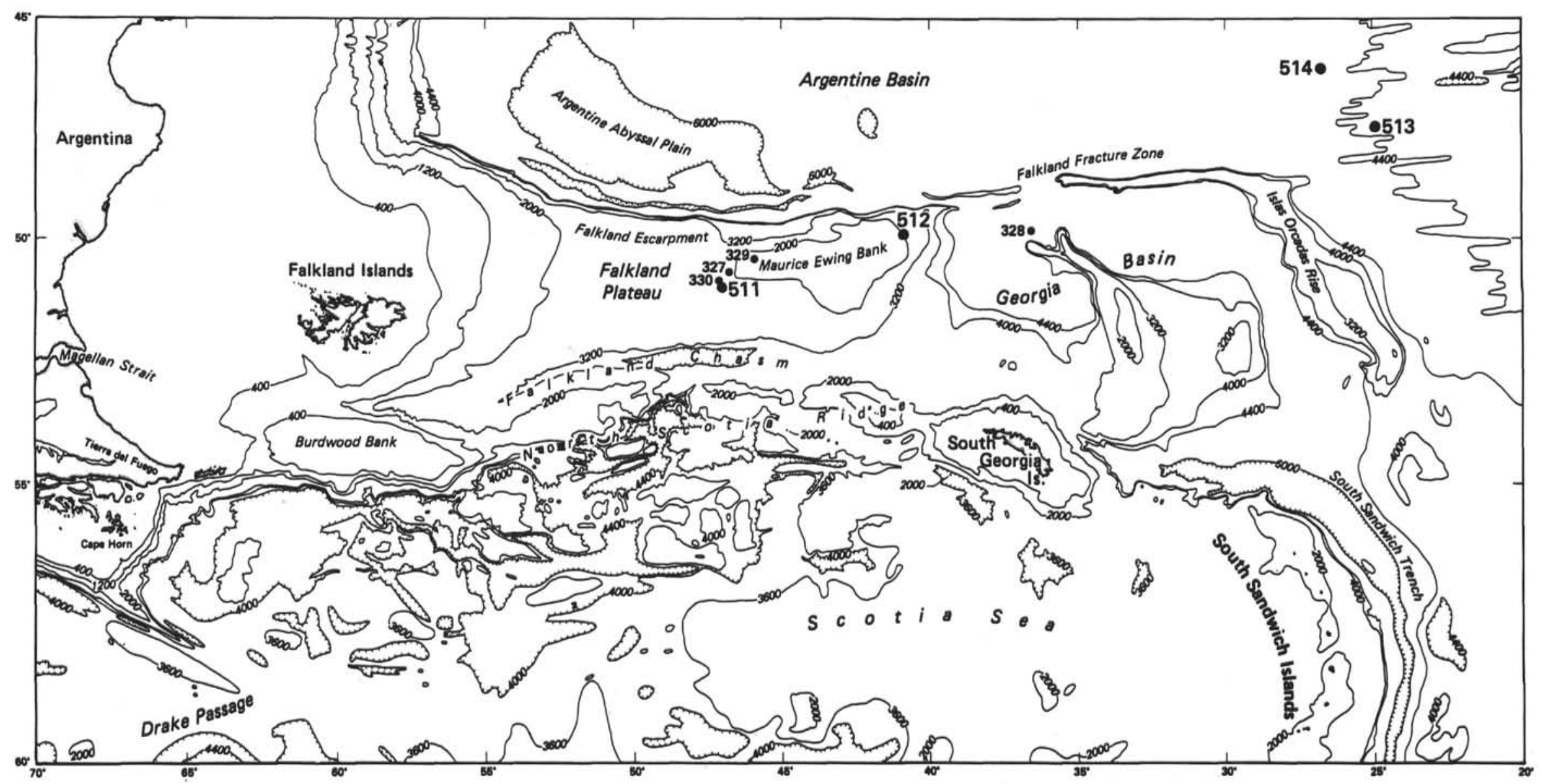

Figure 1. Location of Sites 511, 512, 513, and 514, DSDP Leg 71. 
The results described in this chapter are those from Sites 511, 513, and 514. A complete investigation into the sediments of Site 512 has been carried out by Ledbetter (this volume).

\section{SITE 511}

Site 511 was drilled in the basin province of the Falkland Plateau, on the west of the Maurice Ewing Bank, in $\mathbf{2 6 0 0}$ meters of water. Beneath a thin layer of Pliocene to Recent sands and oozes, 630 meters of Jurassic to Oligocene sediment were penetrated. Cenozoic sediments consisted of olive to gray diatomaceous oozes, often with nannofossils, overlying a small section of gray pelagic clay. Mesozoic sediments consisted of gray, mainly zeolitic clays and oozes overlying reddish brown claystones with muddy nannofossil chalk and thinly laminated black mudstones or black shales. Bioturbation is often seen in the Mesozoic clays, claystones, and chalks.

\section{Stability Tests}

A total of 137 oriented samples were taken from the section. Selected samples were continuously demagnetized at fields up to $600 \mathrm{Oe}$ to test stability. The results are shown in Figure 2. Samples 511-31-3, 99-101 cm (256.00 m), 511-39-1, 93-95 cm (328.94 m), and 511-48-1, $131-133 \mathrm{~cm}(414.82 \mathrm{~m})$, from the gray zeolitic clays and reddish brown claystones, and Sample 511-63-3, 102 $104 \mathrm{~cm}(560.03 \mathrm{~m})$, from the black shales, all show a high degree of stability. Median destructive fields range from 160 Oe to in excess of 300 Oe. Sample 511-63-3, 102-104 cm was demagnetized on land, 12 months postcruise, the other three were demagnetized on board. Sample $511-30-4,30-32 \mathrm{~cm}(245.81 \mathrm{~m})$ is moderately stable up to a field of $150 \mathrm{Oe}$. Initial intensity is less than $1.0 \mu \mathrm{G}$, and median destructive field is low (110 Oe).
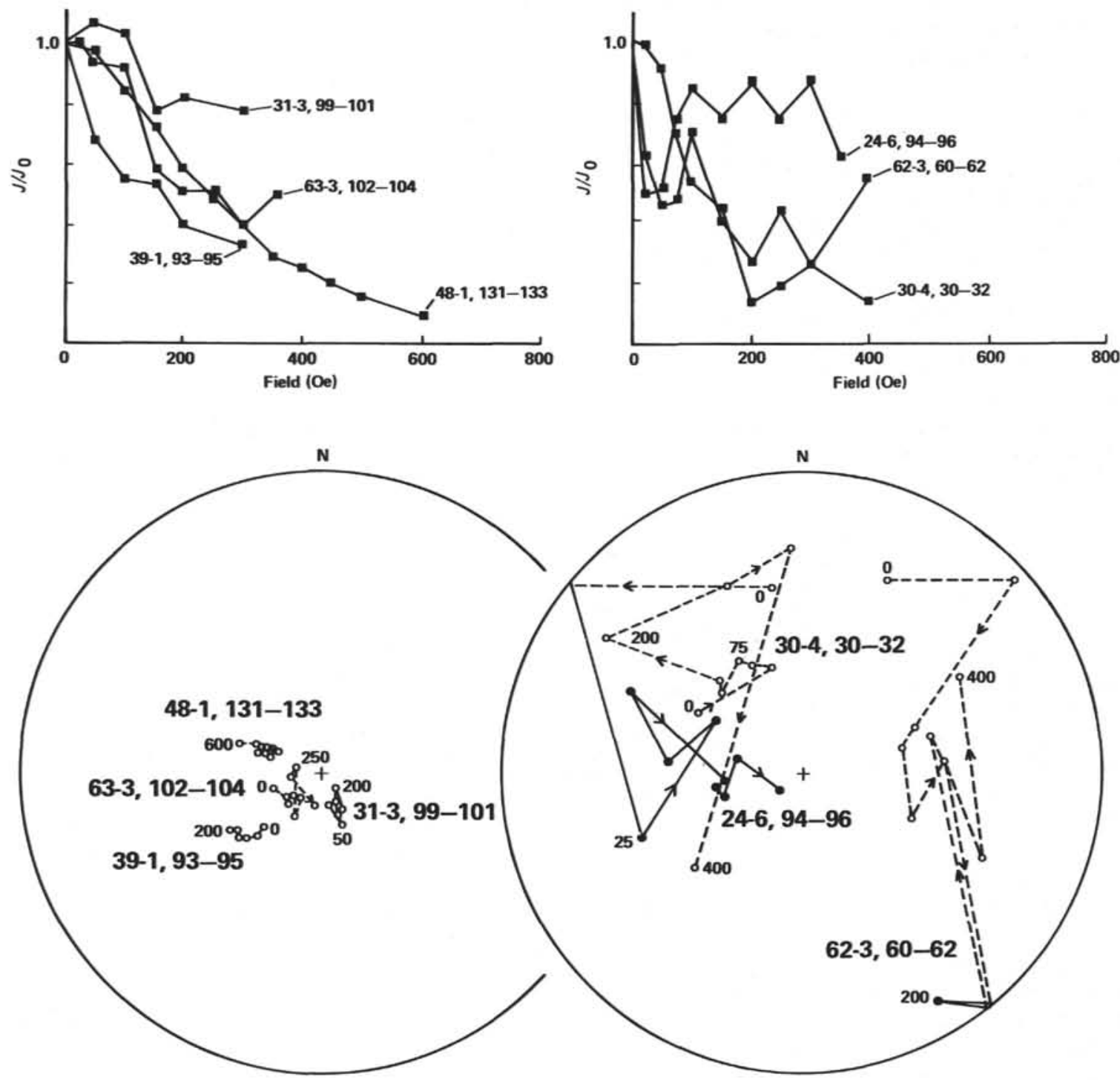

Figure 2. Examples of alternating field demagnetization of samples from Site 511, showing polar stereographic projections (solid symbols: lower hemisphere, positive inclination; open symbols: upper hemisphere, negative inclination. Larger figures refer to sample numbers; other figures refer to peak field). Also shown are plots of normalized intensity against peak demagnetizing field. 
Above 150 Oe the remanent magnetization is very weak, and anomalous directions are produced, possibly because the noise of the instrument is comparatively large. Sample $511-24-6,94-96 \mathrm{~cm}(208.45 \mathrm{~m})$ shows a fairly consistent direction after the initial demagnetization step. This sample probably developed a small secondary magnetization which was removed at 25 Oe. Sample 511-62-3, $60-62 \mathrm{~cm}(550.11 \mathrm{~m})$ appears only moderately stable at fields between 50 and $150 \mathrm{Oe}$. Intensity is low and initially comprised primary and secondary components. Above 150 Oe, behavior is erratic.

\section{Magnetic Polarity}

A field of 150 Oe was chosen for demagnetization of all the remaining samples. Those samples whose NRM intensity was greater than $1.0 \mu \mathrm{G}$ were demagnetized on board Glomar Challenger. These showed only small changes in direction (up to $15^{\circ}$ ). Intensity decreased by an average of $35 \%$. The rest of the samples were demagnetized on land and measured on a cryogenic magnetometer. These samples consisted of the majority of Cenozoic samples, and those from the "black shales." Large changes in direction were noted, especially in the samples from the black shales. Although the growth of secondary magnetizations between shipboard and landbased measurements has been noted (e.g., Hailwood, 1979), it is considered that these demagnetized directions represent true stable magnetizations. The samples were stored in a reduced magnetic field from arrival in Edinburgh until shortly before measurement. Differences in the results probably reflect the greater accuracy of the cryogenic magnetometer, especially with material of extremely low intensity.

Inclination after demagnetization is shown in Figure 3 (cf. NRM values, in the site chapter). Figure 4 shows histograms comparing inclination before and after demagnetization. The mean absolute inclination changes from $52.2 \pm 22.7^{\circ}$ to $54.8 \pm 22.9^{\circ}$ with demagnetization. Figure 4 shows a peak coincident with the present axial dipole field (approximately $-65^{\circ}$ ). This bias toward negative values reflects the dominance of normal polarity during the Cretaceous. There is a slight increase in the number of positive inclinations at $150 \mathrm{Oe}$.

The large number of gaps in sedimentation and the sparse sampling in the upper part of the hole due to poor recovery and drilling disturbance prevent the construction of a polarity reversal sequence for the Cenozoic at Site 511. Inclinations in the Mesozoic can be divided into three broad groups: a zone of normal polarity between Cores 28 and 57 separating two zones of mixed polarity. The zone of normal polarity corresponds to the long Cretaceous normal interval, or Mercanton Normal (van Hinte, 1976). The upper and lower zones of mixed polarity correlate with the Beringov and Serra Geral Mixed Zones, respectively.

Four normal intervals and four reversed intervals are seen in Maestrichtian to Campanian sediment; however, three of the reversed zones and one of the normal zones are represented by single samples. The high inclinations after demagnetization suggest that these samples are reflecting true polarity changes. The broad reversed polar-

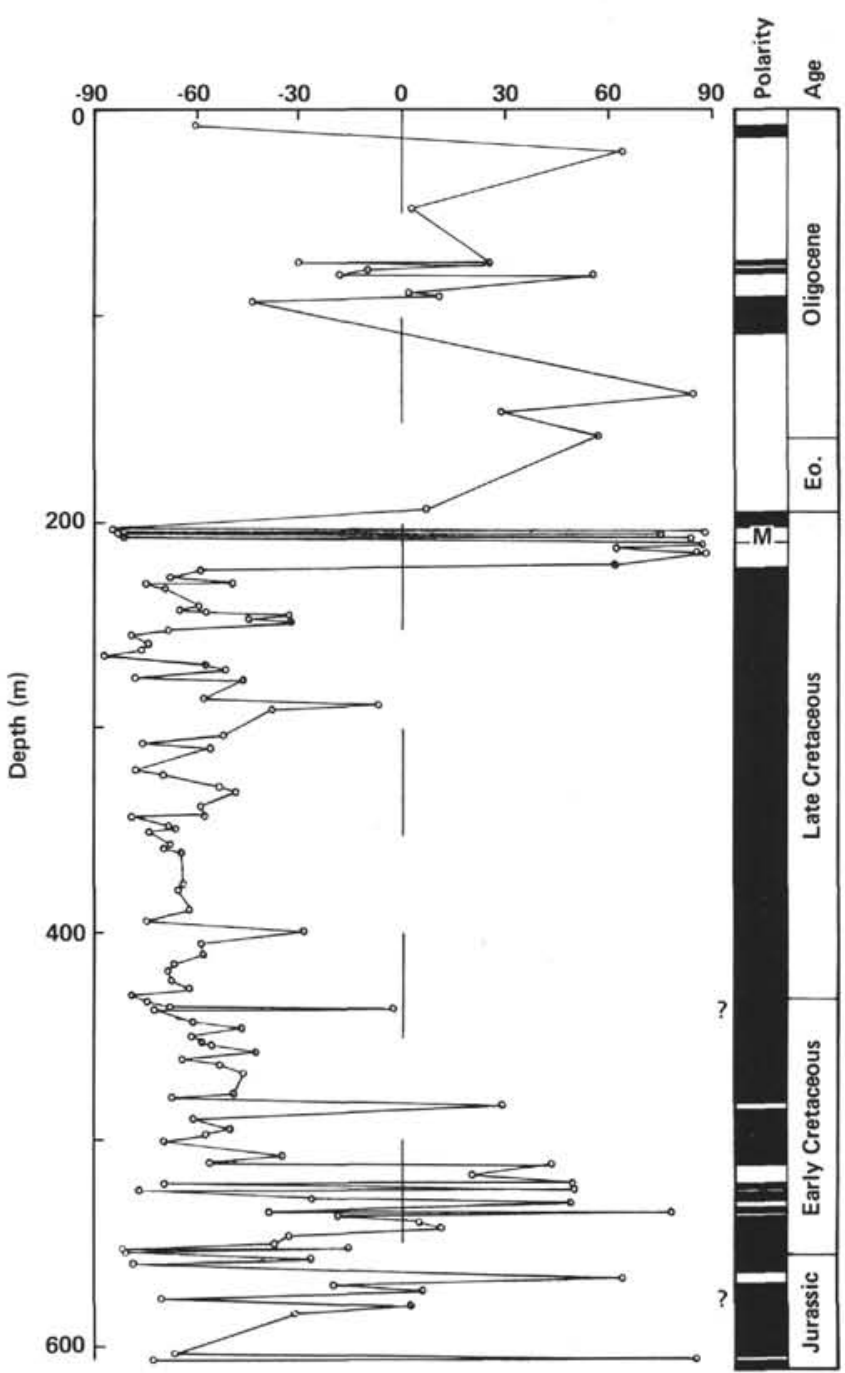

Figure 3. Downhole record of inclinations after demagnetization for Site 511, with inferred polarity (black: normal polarity; white: reversed; M: mixed polarity).

ity zone between depths of 211.45 and 219.61 meters (Samples 511-24-5, 94-96 cm and 511-27-1, 60-62 cm) probably correlates with the interval between Anomalies 31 and 32 . Unfortunately, neither the magnetostratigraphy nor the biostratigraphy are sufficiently accurate to decide between the models for the upper limit of the long Cretaceous normal interval of van Hinte (1976), Keating et al. (1975), or LaBrecque et al. (1977).

The sediments from Core 28 to the bottom of Core 57 $(223.50 \mathrm{~m}-508.50 \mathrm{~m})$ are of normal polarity except for one sample at a depth of 483.58 meters (511-55-3, 57-59 $\mathrm{cm}$ ). A single reversed sample in Core 30 (at $242.81 \mathrm{~m}$ ) becomes normal with demagnetization. In addition, there are two samples of low negative inclination: 511-35-1, $79-81 \mathrm{~cm}(290.80 \mathrm{~m})$ and $511-50-3,65-67 \mathrm{~cm}(436.16$ $\mathrm{m})$. The upper sample of low inclination shows a change from reversed to normal polarity with demagnetization. Samples 511-50-3, 65-67 cm and 511-55-3, 57-59 cm change from normal toward reversed polarities, perhaps indicating that the more stable magnetization is reversed. These two samples are from the lower to middle Albian 

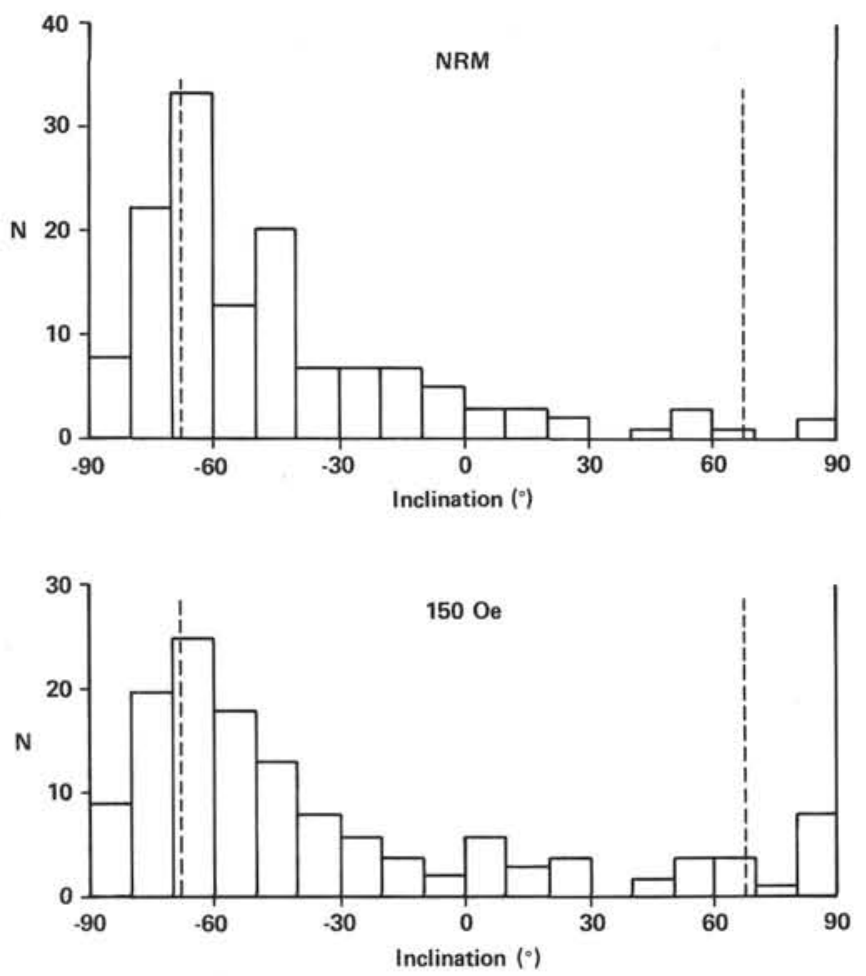

Figure 4. Histograms of inclination, before and after demagnetization, together with the present axial dipole field at Site 511 .

and may correlate with the Site 263 mixed zone of Green and Brecher (1974) and the Gatan Reversal.

The age of the sediments in the lower section of the hole is unclear. Macropaleontology places Cores 63 $(556.00 \mathrm{~m})$ and below in the Jurassic. As many as five reversed intervals may be present in the Lower Cretaceous sediments below Core $58(508.50 \mathrm{~m})$, indicating that these deposits belong to the Serra Geral Mixed Zone. The largest of these reserved zones, between Samples $511-58-4,129-131 \mathrm{~cm}$ and $511-59-2,140-142 \mathrm{~cm}$, is correlated with the interval between Anomalies M3 and M4. Van Hinte places the lower boundary of the long normal interval near the top of the Hauterivian, whereas Larson and Hilde (1975) place it within the Aptian. The Site 511 data is compatible with either model. Although two reversals are seen in Jurassic rocks, paleontological control is not great enough to define these intervals more accurately.

Absolute inclinations average $54.8 \pm 22.9^{\circ}$ throughout the hole after demagnetization; however, the peak in the inclination histogram (Fig. 6) corresponds to $60-70^{\circ}$. According to Smith and Briden (1977), the latitude of the Falkland Plateau varied between 50 and $60^{\circ} \mathrm{S}$ during the Cretaceous and Tertiary. Assuming a geocentric axial dipole, the expected inclination would be between 67 and $74^{\circ}$.

\section{Variation of Intensity and Susceptibility}

Downhole variation of NRM intensity, susceptibility, and lithology are shown in Figure 5.

The Cenozoic muddy diatomaceous oozes, muddy nannofossil diatomaceous oozes, and pelagic clay (Units
$2 \mathrm{~A}$ and $2 \mathrm{~B}$ ) and the Maestrichtian calcareous ooze and zeolitic calcareous ooze (Unit 3) have low intensities (generally less than $1 \mu \mathrm{G}$ ) and fairly low susceptibilities (2.3 $\mu \mathrm{G} / \mathrm{Oe})$, giving low Q-ratios $(0.02-0.30)$. Intensity in the gray zeolitic clays and claystones of Unit 2 is low $(0.5-2.0 \mu \mathrm{G})$ to a depth of approximately 320 meters (Core 38 ), below which values increase to between 20 and $60 \mu \mathrm{G}$. There is much variation, however: Sample $511-45-3,88-90 \mathrm{~cm}$ has an intensity of $131.8 \mu \mathrm{G}$. Susceptibility values in Unit 4 are more consistent, lying between 10 and $50 \mu \mathrm{G} / \mathrm{Oe}$ and showing a slight increase toward the bottom of the unit. Q-ratios remain low (about 0.1 ) to a depth of 320 meters, below which they show large amounts of variation, reaching values in excess of 4. Unit 5, comprising reddish brown claystones, nannofossil claystones, and muddy nannofossil chalks, has fairly high intensities $(5-40 \mu \mathrm{G})$ and fairly high susceptibilities (10-40 $\mu \mathrm{G} / \mathrm{Oe})$, giving Q-ratios of about 1.0. Again there is much variation in intensity and, consequently, in Q-ratio. Intensities in the black mudstones and nannofossil mudstones (or black shales) of Unit 6 have low intensities (0.01-1.00 $\mu \mathrm{G})$ and fairly low susceptibilities (2-10 $\mu \mathrm{G} / \mathrm{Oe})$. Q-ratios for this interval are low; most are less than 0.1.

\section{SITE 513}

A sequence of 387 meters of Lower Oligocene to Recent sediments was recovered from Site 513, which is situated in 4313 meters of water on the lower western flank of the Mid-Atlantic Ridge. The upper part of the sequence consisted of Plio-Pleistocene diatomaceous muds and ooze which were cored to a depth of 104 meters in Hole 513. Hole 513A was washed down to 55 meters; a 20-meter interval missing from the first hole was cored before continuous coring recommenced from 85 meters, the lowest depth of sediment retrieved from Hole 513 . Sediment recovered ranged from lower Oligocene to lower Pliocene and consisted of diatomaceous and nannofossil ooze with some interlayered diatomaceous mud. Bioturbation is variable; the more intense disturbance occurs in the lower half of the sequence, below Core 17. Basement was encountered at a depth of 380.5 meters, and 6 meters of fine-grained basalt were recovered.

\section{Stability Tests}

No samples were taken for paleomagnetic measurement from the sediment of Hole 513, as the deformation caused by drilling was too great. Of the 210 samples collected from the undisturbed sediment of Hole 513A, 16 were demagnetized, stepwise, at fields of up to $600 \mathrm{Oe}$ to test for stability of remanence. Selected results are shown in Figure 6. The majority of the samples show a high degree of stability.

Samples 513A-4-3, 100-102 cm, 513A-6-5, 50-52 cm and $513 \mathrm{~A}-11-7,16-18 \mathrm{~cm}$ are very stable, showing almost no change in direction with demagnetization apart from small changes at 350 Oe in Sample 513A-6-5, 50-52 cm. Intensity decreases uniformly with demagnetization, and median destructive fields vary from 270 Oe to in excess of 350 Oe. Samples 513A-15-1, 113-115 cm and 513A$21-5,38-40 \mathrm{~cm}$ are fairly stable, changing by $30^{\circ}$ through- 


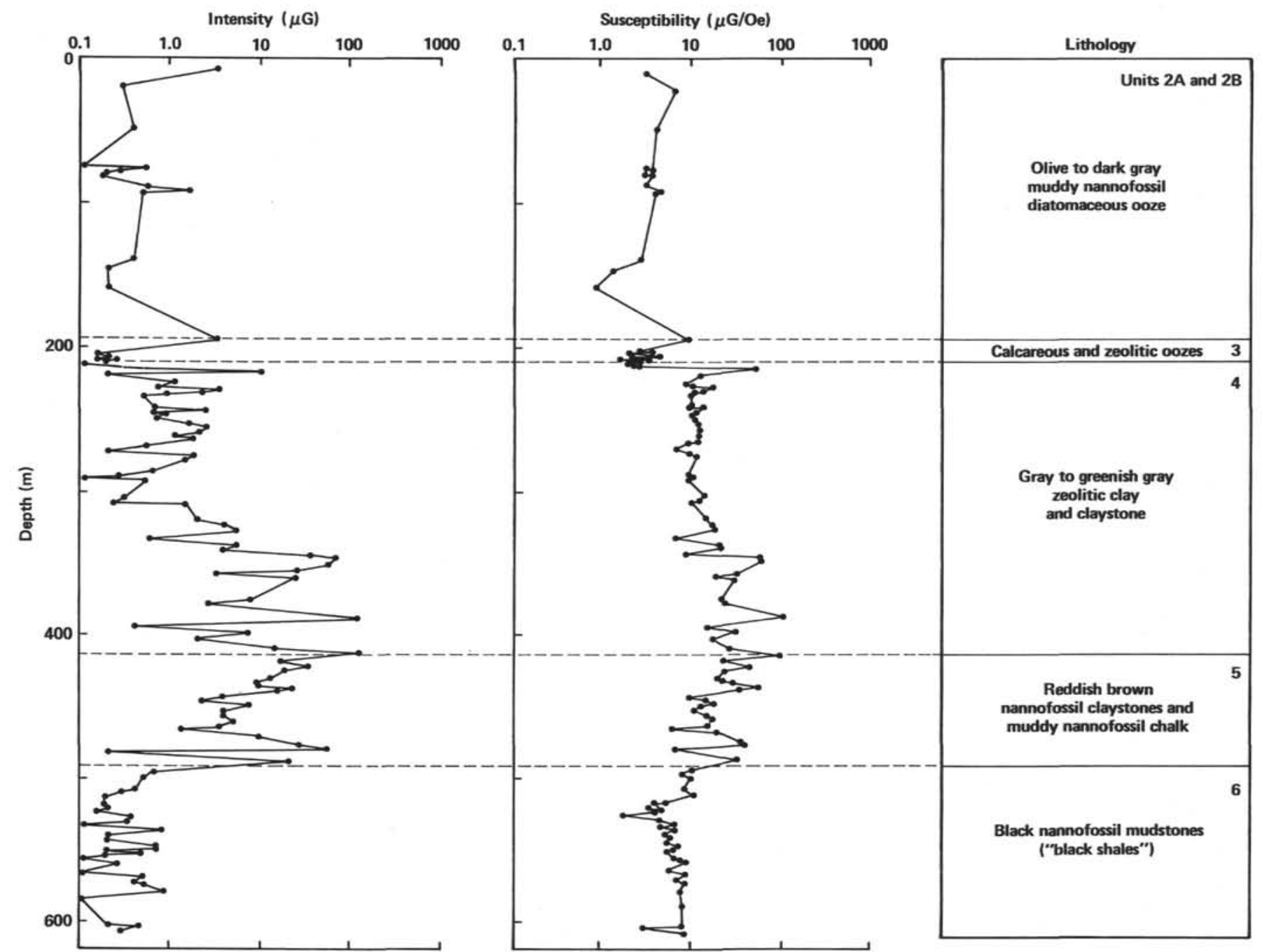

Figure 5. Downhole variation of intensity and susceptibility with lithology at Site 511.

out demagnetization. Intensity decrease is not always uniform, however; in Sample 513A-21-5, 38-40 cm the median destructive field is not reached at $350 \mathrm{Oe}$. Sample 513A-15-1, 113-115 cm has a low median destructive field $(53.7 \mathrm{Oe})$.

The remaining samples show lesser degrees of stability. $513 \mathrm{~A}-8-1,120-122 \mathrm{~cm}$ is apparently stable up to 300 Oe, whereas 513A-18-3, 54-56 cm shows the removal of a secondary magnetization at $25 \mathrm{Oe}$, stability up to about $100 \mathrm{Oe}$, then variation of $50^{\circ}$ about the stable direction. In these cases NRM intensity is less than $1.0 \mu \mathrm{G}$, and median destructive fields are generally between 75 and $200 \mathrm{Oe}$.

\section{Magnetic Polarity}

The remaining samples were demagnetized at a field of $150 \mathrm{Oe}$. The majority of these demagnetizations were carried out on land; however, a few of the stronger samples were demagnetized on board. Average mean intensity was reduced by over $60 \%$, but the vast majority of the samples changed direction by less than $20^{\circ}$ with demagnetization. Mean, absolute inclination was $44.3 \pm$ $23.0^{\circ}$ before and $48.2 \pm 22.6^{\circ}$ after demagnetization.
Histograms of inclination before and after are plotted in Figure 7. At NRM there is a double peak at high negative inclinations and a broad distribution among remaining directions. At $\mathbf{1 5 0}$ Oe there is a movement toward bimodality, biased toward negative inclinations; however, a large number of samples remain with intermediate inclinations. The negative inclinations are centered around the present axial dipole field, and positive values are centered between 50 and $60^{\circ}$. This shift in the values for reversed polarity and the large number of intermediate directions indicate that a normal overprint may still be present in some of the samples. Inclination after demagnetization is plotted against depth in Figure 8.

Using biostratigraphic guidelines (see site chapter), the upper Miocene section can be correlated with the magnetostratigraphy of LaBrecque et al. (1977) (see Fig. 9). Core 4, which is normally magnetized except for two samples with low positive inclinations, is assigned to Epoch 5 (Anomaly 3A). The reversed interval in Core 5 may be the event within Epoch 5 or the start of Epoch 6 . A period of low sedimentation rate, or possibly an unconformity, occurs near the bottom of Core 5 (between 

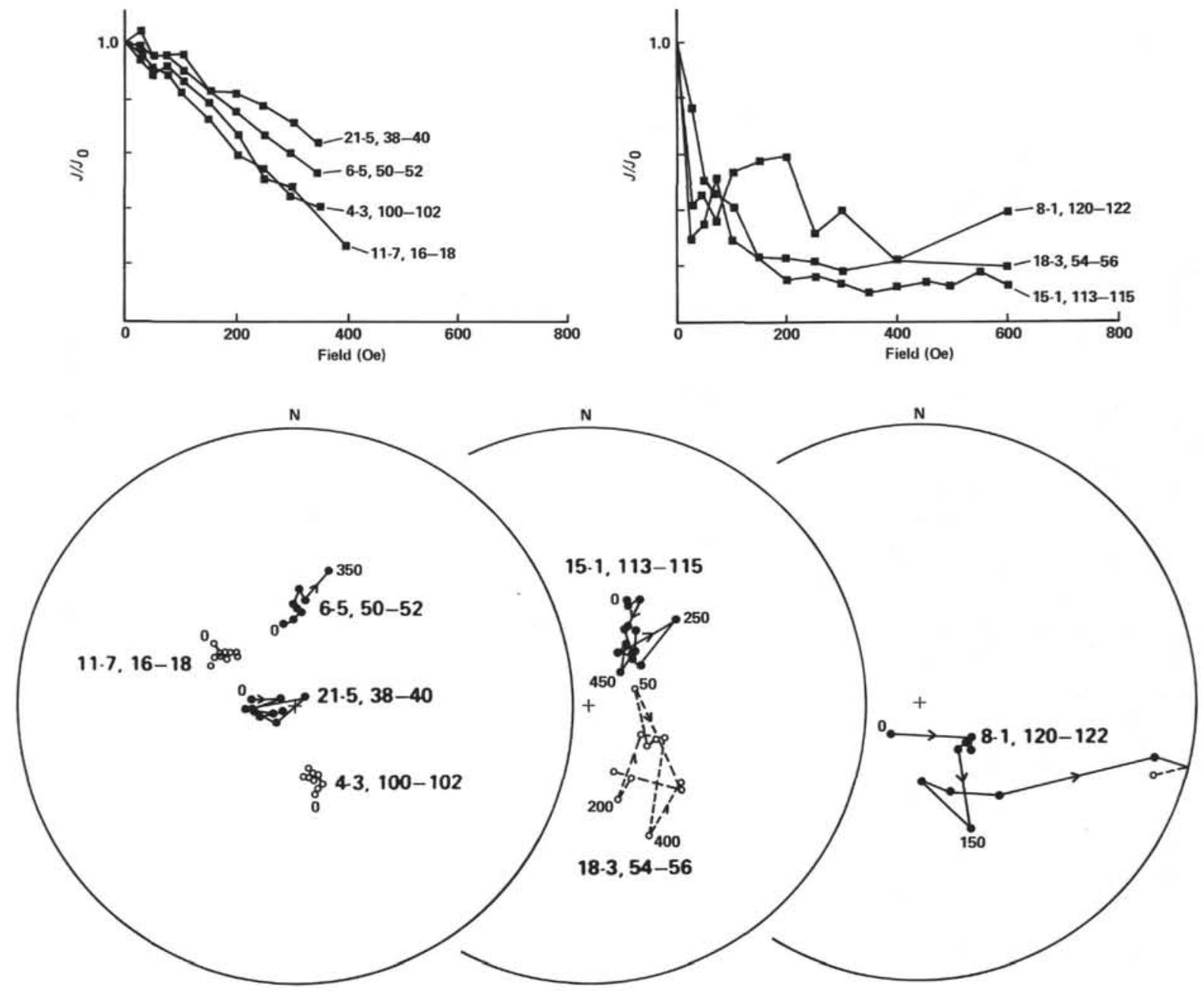

Figure 6. Examples of AF demagnetization of samples from Site 513.
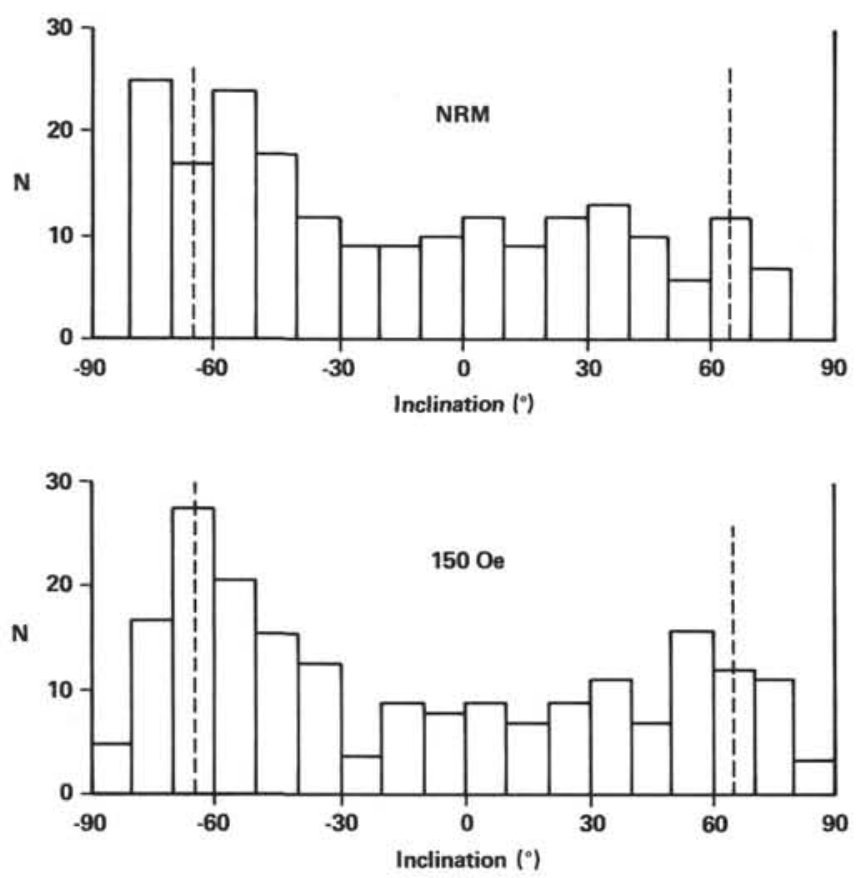

Figure 7. Histograms comparing inclinations of Site 513 before and after demagnetization together with the present axial dipole field. depths of 111.41 and $112.38 \mathrm{~m}$ ). The remainder of Epoch 6 is probably missing. Core 6 to the upper part of Core 10 is assigned to Epoch 7 (Anomalies 4 and 4A). During this period, accumulation rate is estimated to be about $100 \mathrm{~m} / \mathrm{m}$.y. The reversal in Core 8 then corresponds to the large reversal interval in the middle of Epoch 7.

Samples in the lower half of Core 10 are of mixed polarity, possibly correlating with Epoch 8 . Sedimentation rate is slow in this part of the core, and some material may be missing. Alternatively, Epoch 8 may not occur until the lower half of Core 11, below which recovery was low. Core 12 is correlated with Epoch 9 (Anomaly 5). Unfortunately, little was recovered in Cores 13 and 14 , in which the Miocene/Oligocene boundary is thought to have occurred. Core 15 , which is reversed, may correlate with the interval between Anomalies $6 \mathrm{C}$ and 7, with Cores 16 to 21 equaling Anomalies 7 to 9 .

Basaltic basement was reached at the bottom of the hole. These rocks were reversely magnetized (see site chapter) and probably lie just above Anomaly 15, at the junction of the Eocene and Oligocene. Correlation of the scattered samples between Cores 21 and 35 is not possible directly because of poor recovery; however, average sedimentation rate between Cores 23 and 24 (the 


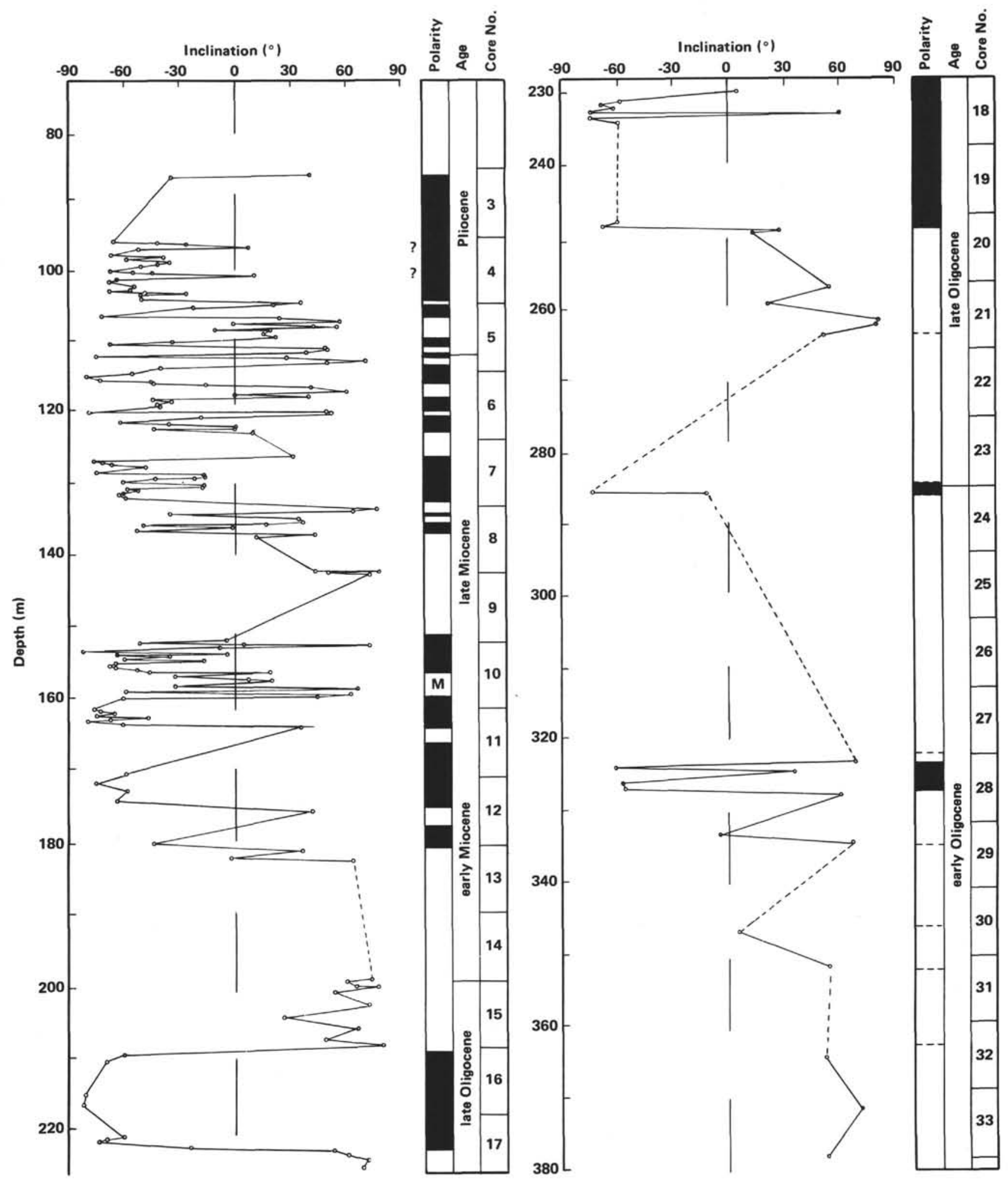

Figure 8. Downhole record of inclination for Site 513 after demagnetization, together with inferred polarity. (M, mixed polarity.) 


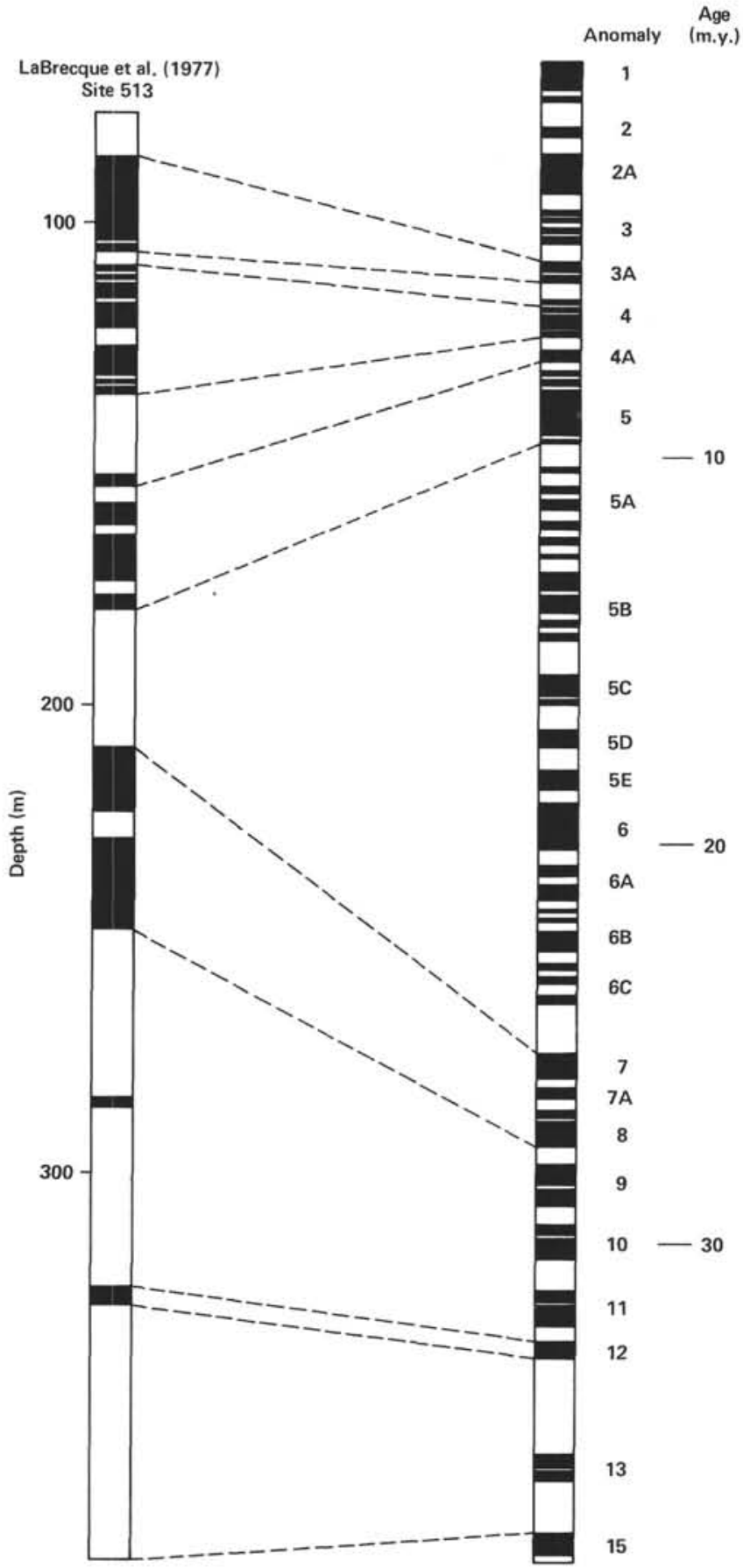

Figure 9. Magnetostratigraphy for Site 513 compared with that of LaBrecque et al. (1977).

P21/P20 foraminiferal boundary) and the bottom of the hole can be used to correlate Core 28 with Anomaly 12. The lower part of the hole below Core 28 is predominantly reversed, correlating with the largely reversed polarity of the Rupelian Stage (LaBrecque et al. 1977). Unfortunately, Anomaly 13 is not seen, because of low recovery in Cores 29-32.

\section{Variation in Intensity and Susceptibility}

NRM intensity, together with susceptibility and lithology, are presented in Figure 10. Intensity and sus- ceptibility are fairly constant, at values from 0.5 to 1.0 $\mu \mathrm{G}$, and 5 to $10 \mu \mathrm{G} / \mathrm{Oe}$, to a depth of about 180 meters (the limit of Unit I, a muddy diatomaceous ooze). Below 180 meters, intensity and susceptibility both decrease with depth, averaging $0.1 \mu \mathrm{G}$ and $1.0 \mu \mathrm{G} / \mathrm{Oe}$, respectively, at the bottom of the hole. Q-ratios, apart from one or two apparently anomalous cases, are constant at 0.1 throughout the hole.

\section{SITE 514}

Site 514 is situated in 4318 meters of water, on the lower flank of the Mid-Atlantic Ridge, to the east of the Argentine Basin, about 150 miles north of Site 513 . Over 150 meters of Pliocene to Quaternary sediments were retrieved using the hydraulic piston corer. The sediments are mainly diatomaceous muds, oozes, and clays, with a layer of gray nannofossil muds occurring toward the bottom of the hole. Bioturbation is common but of only minor intensity throughout the hole. Recovery was high $(92 \%)$; however, there was a significant gap due to nonrecovery of Core 7.

\section{Paleomagnetic Measurements}

A total of 492 samples were taken from the undisturbed parts of the core. Contamination of the top of the cores by drill pipe rust was seen in a number of cases. In addition, disturbance occurred at the bottom of some of the cores, possibly because of incomplete extension of the core barrel which led to flow of sediment over the piston at the base of the core.

The NRM of all samples was measured on land, after storage in a reduced field for at least one month, which should allow any anomalous secondary magnetizations to decay. Some of the samples had previously been measured on board Glomar Challenger. The two sets of results show very close agreement, indicating that the magnetization is stable.

As a further test of stability, a number of samples were demagnetized at fields of up to 600 Oe (Figs. 11, 12 , and 13). Many samples have a high degree of stability, their direction of magnetization showing little change with demagnetization. Others show either small initial changes because of the removal of a secondary magnetization or the development of anomalous magnetizations at higher fields. A few display erratic behavior.

Figure 11 shows five samples representative of those with high stability. The samples have NRM intensities in the range 1.0 to $5.0 \mu \mathrm{G}$. Median destructive fields vary from 180 to over 330 Oe. Directions are constant with demagnetization; inclinations remain at about $50^{\circ}$.

Figure 12 shows samples of moderately high stability. Samples 514-8-2, 49-51 cm and 514-29-2, 90-92 cm change little in direction with demagnetization up to 400 Oe, then show a change in direction of remanence accompanied by a rise in intensity. Sample 514-3-2, 116$118 \mathrm{~cm}$ shows stability up to $200 \mathrm{Oe}$, then a change in direction. Intensity in these samples varies between $0.9 \mu \mathrm{G}$ and $7.7 \mu \mathrm{G}$. Median destructive fields are about $100 \mathrm{Oe}$ for 514-3-2, 116-118 cm and 514-8-2, 49-51 cm and almost 300 Oe for $514-29-2,90-92 \mathrm{~cm}$. The anomalous behavior may represent the acquisition of an anhysteretic 


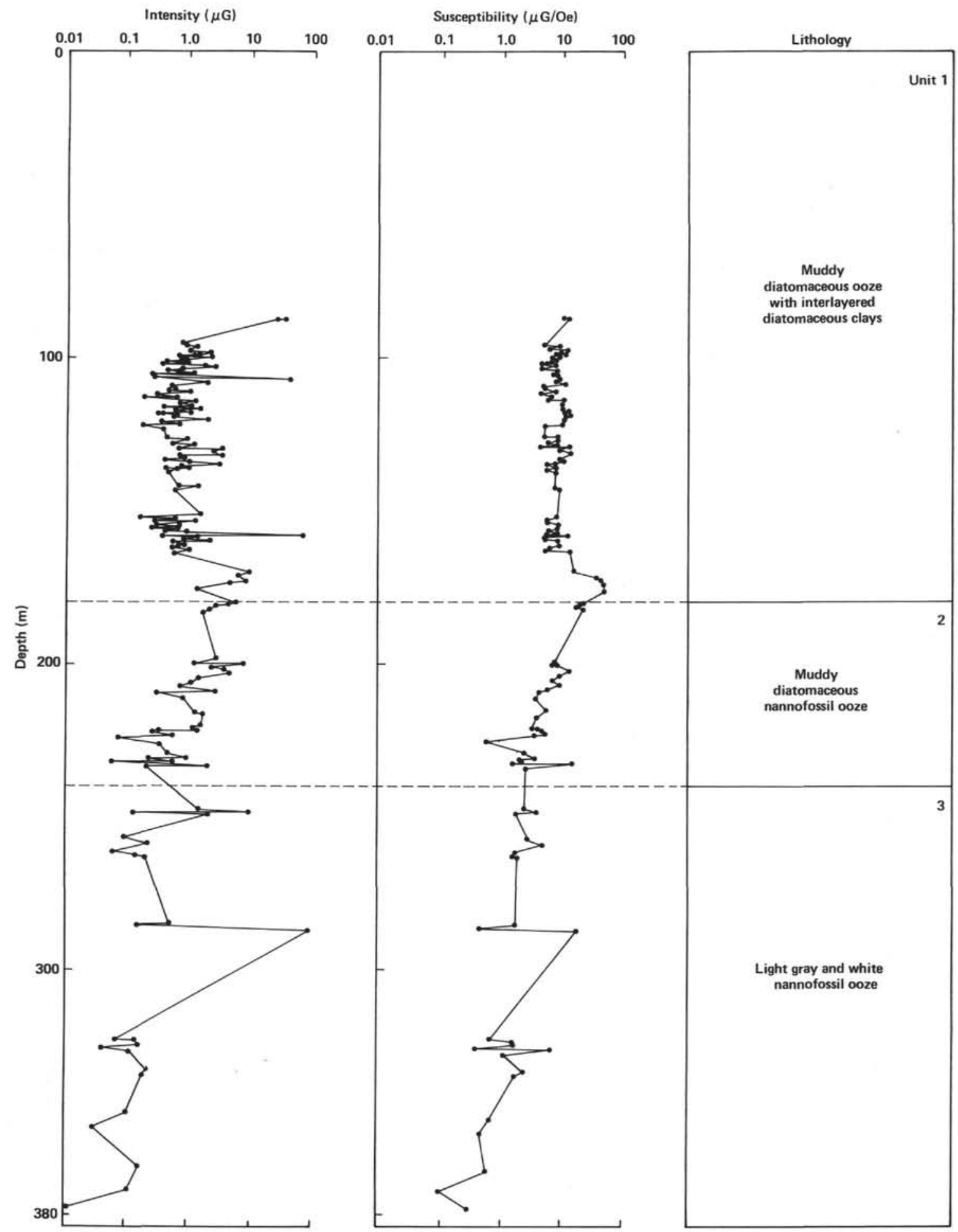

Figure 10. Variations of intensity, susceptibility, and lithology at Site 513.

remanent magnetization (ARM) owing to the demagnetization process. Sample 514-21-3, 112-114 cm displays a marked decrease in intensity between NRM and $25 \mathrm{Oe}$, accompanied by a change of $20^{\circ}$ in inclination. This probably represents the removal of a secondary magnetization. The low median destructive field $(47.6 \mathrm{Oe})$ indicates low average coercivity of the magnetic minerals, hence their readiness to acquire a secondary magnetization. Again an ARM is seen above 400 Oe.

Figure 13 shows a number of abnormal results. Some of these samples occur within, or just above, polarity transitions.

1) Sample $514-4-3,5-7 \mathrm{~cm}$ is reversed at NRM but gradually changes direction to become normal above 

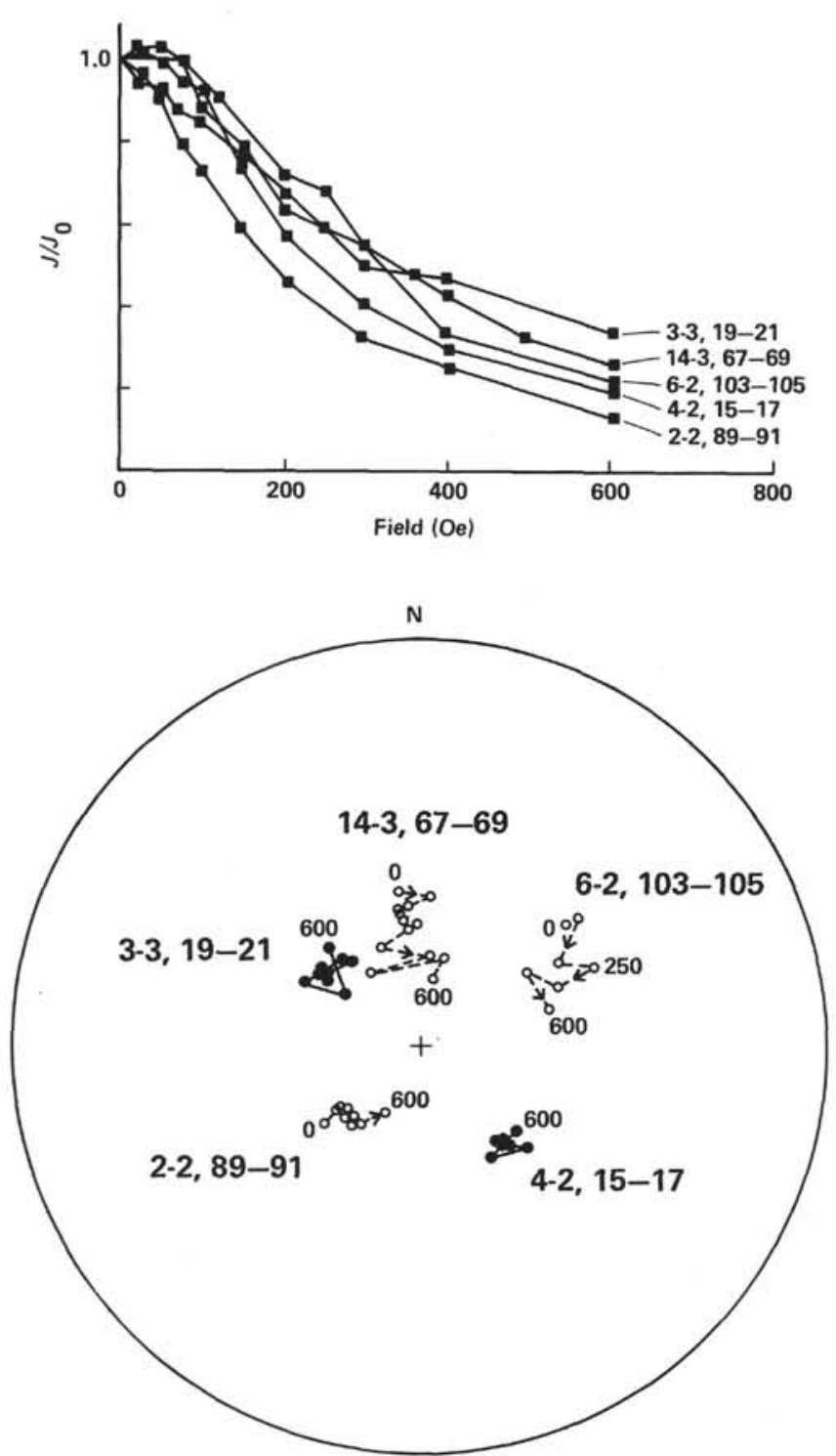

Figure 11. Examples of AF demagnetization of stable samples from Site 514.

400 Oe. Relative declination changes from $90^{\circ}$ to $140^{\circ}$, and inclination changes from $30^{\circ}$ to -30 . The median destructive field is high (316.7 Oe). This sample is within the upper Jaramillo transition.

2) Sample 514-6-2, 52-54 cm lies just above the lower Olduvai transition. Magnetization is initially normal, with an inclination of $35^{\circ}$. This increases with demagnetization up to 80 at $200 \mathrm{Oe}$, and intensity decreases rapidly (median destructive field is $82.3 \mathrm{Oe}$ ). Above $200 \mathrm{Oe}$, intensity increases slightly and inclination decreases to about $20^{\circ}$.

3) Sample 514-11-2, 43-45 cm shows two directions, an initial direction (declination $=120^{\circ}$, inclination = $\left.50^{\circ}\right)$ stable up to $100 \mathrm{Oe}$ and an endpoint $\left(80^{\circ}, 30^{\circ}\right)$ stable after $300 \mathrm{Oe}$. The median destructive field is $229.1 \mathrm{Oe}$.

4) Sample $514-21-3,74-76 \mathrm{~cm}$ is initially normal with low inclination. Remanent magnetization tends toward stability between 200 and 300 Oe, with a reversed inclination of about $20^{\circ}$. Above 300 Oe an ARM is appar- ently developed. This sample is in the upper Kaena reversal.

5) Sample $514-25-1,45-47 \mathrm{~cm}$, which is normally magnetized at NRM, reverses polarity gradually without reaching a stable endpoint. Reversed inclinations are generally low. Median destructive field is low, about 70 Oe, but intensity increases above $300 \mathrm{Oe}$. This sample is within the upper Mammoth transition.

6) Sample 514-27-1, 71-73 cm lies in the upper part of the upper Cochiti reversal. The magnetization is fairly stable up to $200 \mathrm{Oe}$, then reverses to become normally magnetized, but with a low inclination, at $400 \mathrm{Oe}$. At $500 \mathrm{Oe}$, the sample becomes reversed again. Intensity, which is initially low $(0.20 \mu \mathrm{G})$, changes erratically with demagnetization.

7) Sample 514-32-1, 92-94 cm has a very low initial intensity and is normally magnetized. This sample belongs to an anomalous zone comprising four or five samples. 514-32-1, 92-94 cm reverses after $25 \mathrm{Oe}$ and intensity increases, indicating that the low initial intensity was caused by two almost equal but opposite magnetizations. The sample shows some stability between 150 and 400 Oe. Other samples (e.g., 514-32-1, 129-131 cm) from this anomalous zone show fairly stable, normal magnetizations.

A field of 200 Oe was chosen for demagnetization of the remaining samples. Absolute inclination averaged $51.0 \pm 17.0^{\circ}$ before, and $53.5 \pm 16.6^{\circ}$ after, demagnetization. Figure 14 illustrates the range of values. Bimodality is marked, even before demagnetization; however, the peak values lie between 50 and $60^{\circ}$, indicating some inclination error present (a geocentric axial dipole would give an inclination at Site 514 of $64.2^{\circ}$ ).

\section{Magnetostratigraphy}

Figure 15 shows a downhole plot of inclination and declination after demagnetization, together with NRM intensity and virtual geomagnetic pole latitude. Inclination changes are marked and can be used to define polarity alone. Declination values differ between cores; however, values within a single core are constant, and when polarity-shown by inclination-changes, there is a corresponding change of $180^{\circ}$ in declination. The values of declination shown in Figure 15 are rotated so that the average declination corresponds to zero (or $180^{\circ}$, depending on polarity). Virtual geomagnetic pole (VGP) latitude was calculated using these corrected declinations. Eleven samples were found to have anomalously high intensity as well as directions different from the remainder of the core. These samples occurred at the top or bottom of the core and probably contain some rust contamination. They are omitted from Figure 15.

Five intervals of normal polarity (negative inclination), and five intervals of reversed polarity occur. In addition, there are a number of smaller intervals represented by one or two samples. Corrected declination mirrors these intervals, although there are some inaccuracies.

The upper normal interval is recognized as the Brunhes Epoch. An excursion of low inclination is seen at a depth of 5.25 meters, represented by two samples 

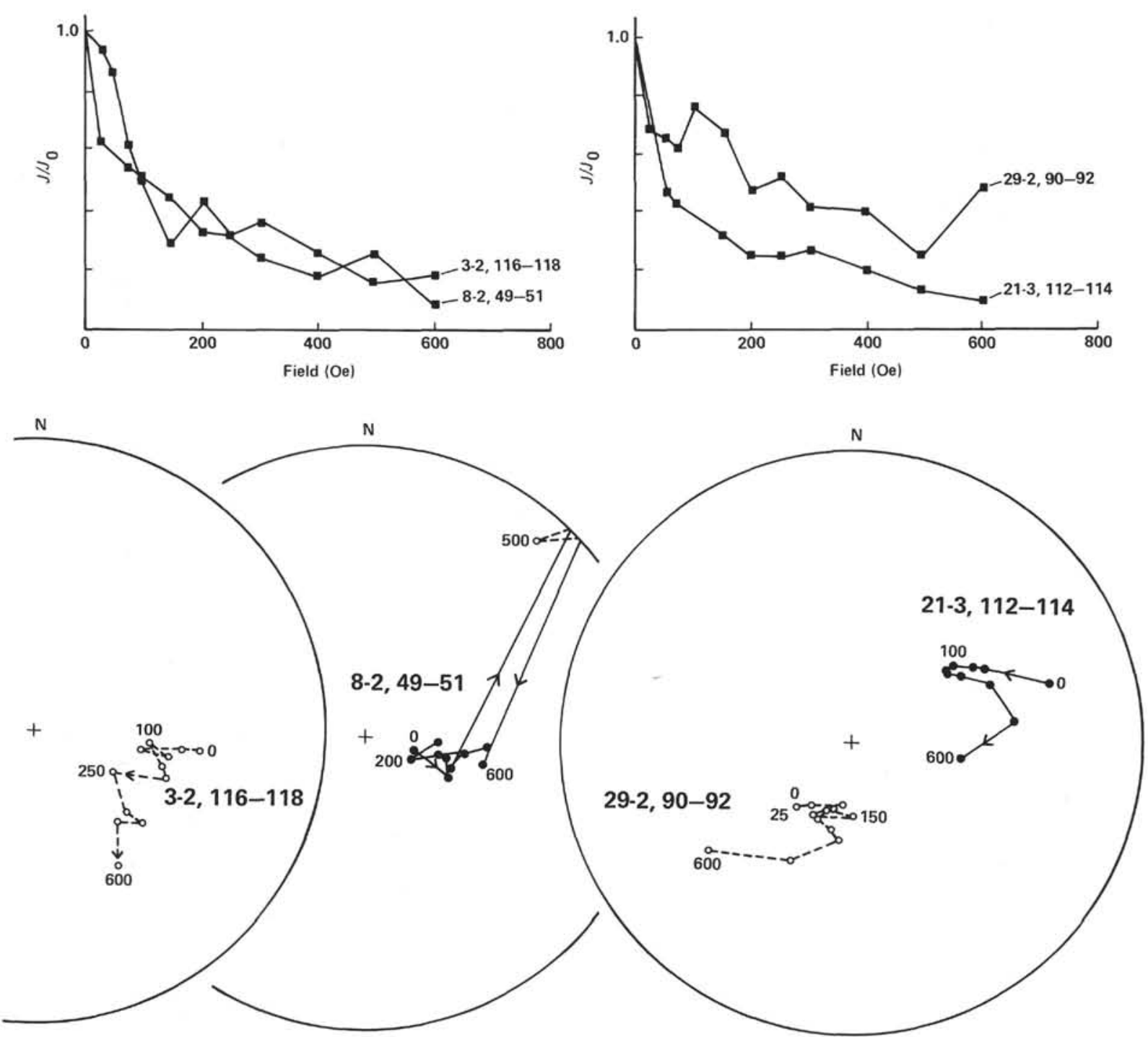

Figure 12. Examples of AF demagnetization of samples from Site 514 with moderate stability.

(514-2-3, 100-102 cm and 514-2-3, 104-106 cm). Taking an average sedimentation rate between the top of the hole and the Brunhes/Matuyama boundary gives an age of approximately 450,000 years for this excursion.

The predominantly reversed interval between 8.28 and 45.00 meters is interpreted as the Matuyama Epoch with the Olduvai Event between 18.60 and 21.37 meters. A short reversal at 13.11 to 13.36 meters is probably the Jaramillo Event. This interval is shorter than would be expected, but this may be because of slow sedimentation rate, or erosion. The Reunion Events are not seen. However, assuming constant sedimentation rate below the Olduvai, they would have been expected to occur in Core 7, which was not recovered.

The Gauss Normal Epoch upper boundary occurs at approximately 45 meters, but the lower boundary is not seen. Cores 15-27 (59.73-115.66 m) are assigned to two diatom zones (Ciesielski, this volume) which can be correlated from the Gauss Epoch above the Kaena Event to the Gilbert Epoch, below the Cochiti Event. Cores 28-
35 (115.6 $\mathrm{m}$ to the base of the hole) are assigned to the Nitzschia praeinterfrigidaria and $N$. angulata diatom zones, which correlate with the Gilbert Epoch, between the Cochiti and Nunivak Events (see Hole 514, site chapter, this volume). Only three reversed and three normal intervals are present between $\mathbf{4 5}$ meters and the bottom of the hole, so erosion has removed at least one interval of each polarity. A hiatus is placed at the bottom of Core $26(110.57 \mathrm{~m})$. This would imply that the lower Gauss and Upper Gilbert epochs were missing and that the Mammoth event occurs directly above the Cochiti Event. In fact, the upper boundary of the Cochiti Event is seen at the top of Core 27.

A small, normal interval is seen below the Cochiti Event, represented by five samples (514-32-1, 92-94 cm to $514-32-1,129-131 \mathrm{~cm})$. These samples have low positive or high negative inclinations. Taking the base of the hole as just younger than the Nunivak Event (4.05 my [Mankinen and Dalrymple, 1979]), and assuming constant sedimentation rate between the base of the Cochiti 

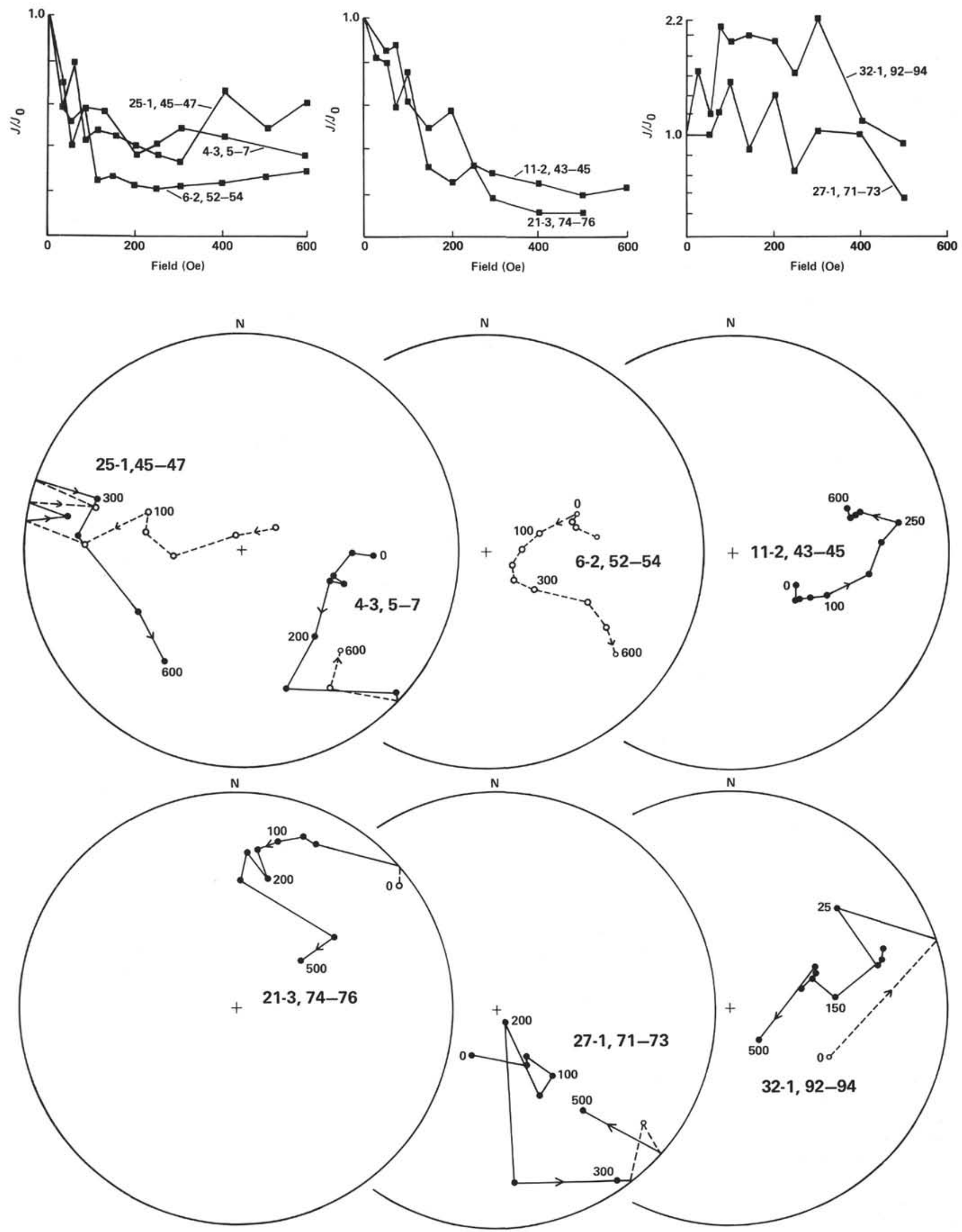

Figure 13. Examples of irregular demagnetization of samples from Site 514. 

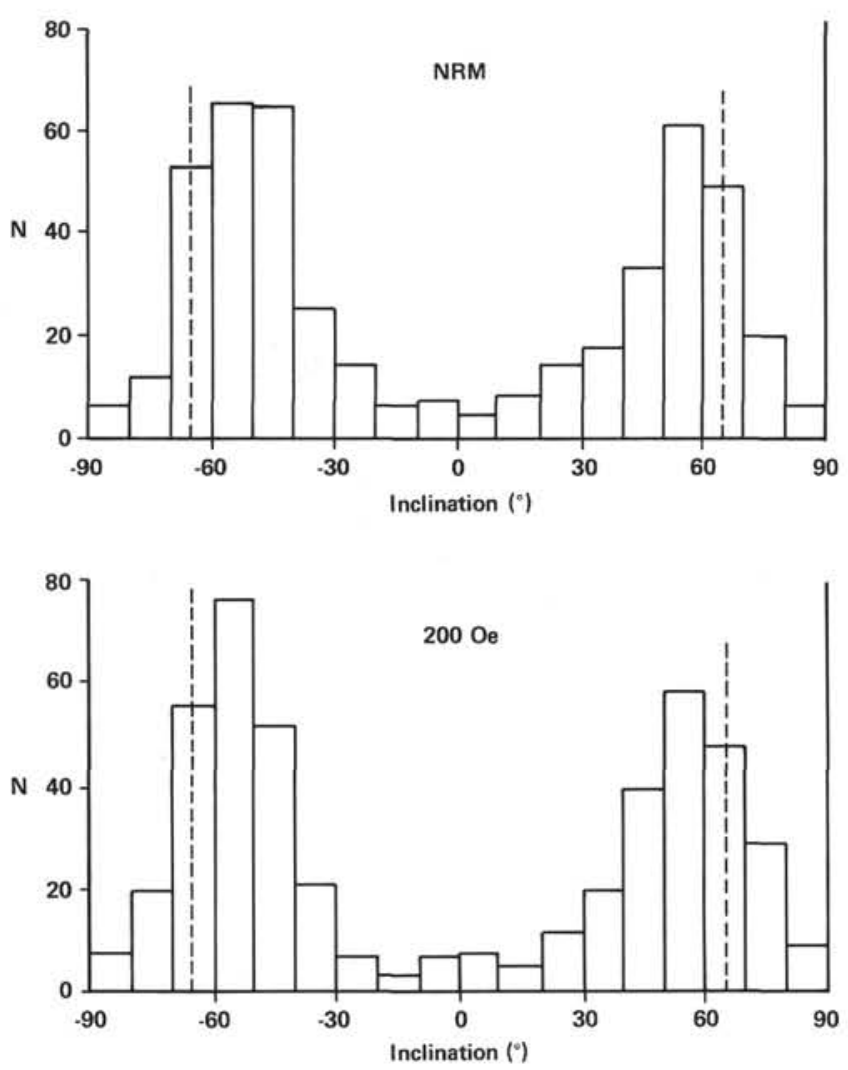

Figure 14. Histograms comparing inclination before and after demagnetization with the axial dipole for Site 514 .

Event and the base of the hole, this excursion, between depths of 134.13 and 134.60 meters is dated at 4.00 m.y., with a duration of only 3000 years.

\section{Polarity Transitions}

The high sedimentation rate provides an opportunity to study the behavior of the geomagnetic field during polarity transitions. The cores were resampled across reversals at intervals of approximately $5 \mathrm{~cm}$. All samples within the transitions were demagnetized, stepwise; although most were stable-e.g., 514-6-2, 103-105 cm-a few showed irregular behavior (as noted earlier). Inclination, declination, intensity, and VGP latitude for each of the 10 recorded polarity transitions are shown in Figure 16 . Of these, only the Brunhes/Matuyama boundary represents an epoch boundary; the others mark event boundaries. The Brunhes/Matuyama boundary is abrupt, with a change of VGP latitude from $61.1^{\circ} \mathrm{N}$ to $57.6^{\circ} \mathrm{S}$ within $2 \mathrm{~cm}$. In the remaining reversals there is at least one intermediate direction and often a short Uturn in the path of the virtual geomagnetic pole.

Errors in the position of the virtual geomagnetic pole may arise from inaccuracies in the average core declination and from inclination errors. When taking the average direction for each core, values with intermediate inclination were omitted. Cones of $95 \%$ confidence about the mean direction commonly have half-angles of less than $10^{\circ}$. This gives an oval of confidence (McElhinny, 1973) about the pole position calculated for each core with an error of $10-15^{\circ}$ along the mean declination (i.e., error in latitude) and of between 7 and $10^{\circ}$ perpendicular to it (i.e., in longitude). This ellipse does not include the present geographic poles because of depositional error of approximately $10^{\circ}$. The errors in VGP position are much smaller than the variation shown by the VGP during a transition.

Virtual geomagnetic pole positions are listed in Table 1 and shown in Figure 17. Those calculated from samples with irregular demagnetization paths are noted in the table. The demagnetization paths of some of the samples (514-4-3, 5-7 cm; 514-6-2, 52-54 cm; 514-21-3, $74-76 \mathrm{~cm} ; 514-25-1,45-47 \mathrm{~cm}$; and 514-27-1, 71-73 cm) show magnetization directions moving from an NRM which agrees with other samples higher in the section toward endpoints which are more characteristic of the sediments below. The NRM is thus composed of a more stable magnetization aligned along the ambient magnetic field during deposition and an additional magnetization formed shortly afterward, after a polarity reversal, which is parallel to the new ambient field. This supports suggestions that acquisition of remanence in deep sea sediments occurs some time after deposition (e.g., Verosub, 1977).

The Jaramillo Event shows a westward swing of the VGP path, during the lower reversal, from a latitude of $150^{\circ} \mathrm{W}$ to $8.6^{\circ} \mathrm{W}$. The upper reversal is fairly sharp, crossing the equator at $10^{\circ} \mathrm{E}$. Neither path shows any resemblance to those reported by Hammond et al. (1979) or Opdyke et al. (1973).

The upper Olduvai transition passed through the Indian Ocean but appears to have returned to low latitudes in the southwest Pacific before stabilizing near the south pole. Hammond et al. (1979) report a VGP path crossing the equator at about $40^{\circ} \mathrm{E}$; Opdyke et al. (1973) show a path crossing at $0^{\circ}$. These are included in Figure 17 for comparison.

The lower Olduvai transition is complex, involving three complete changes in polarity, each path taking a different course. The final path, passing through the Indian Ocean, is in agreement with that reported by Hammond et al. (1979), but in this case no intermediate poles are seen to confirm this path. The transition lasted about 80,000 years.

The upper Kaena and Mammoth transitions both show small excursions of the VGP position back toward low latitudes after the reversals. Unstable samples are seen in both transitions (514-21-3, 74-76 cm and 514-25$1,45-47 \mathrm{~cm}$ ); if these are included, the excursions are seen to involve complete reversals. The lower Kaena transition also shows a reversal of the path, but this occurs before the pole has reached high southerly latitudes.

The upper Cochiti reversal contains a short excursion before the reversal, which is relatively straightforward, although a small amount of westward drift occurs. The lower Cochiti reversal involves both eastward and westward drift while the VGP is in low latitudes. The pole drifts, repeatedly, between $100^{\circ} \mathrm{E}$ and $170^{\circ} \mathrm{W}$.

During the 10 recorded reversals, the VGP path crosses the equator at least 14 times. There does not seem to be a dominant orientation for these paths. There is a lit- 


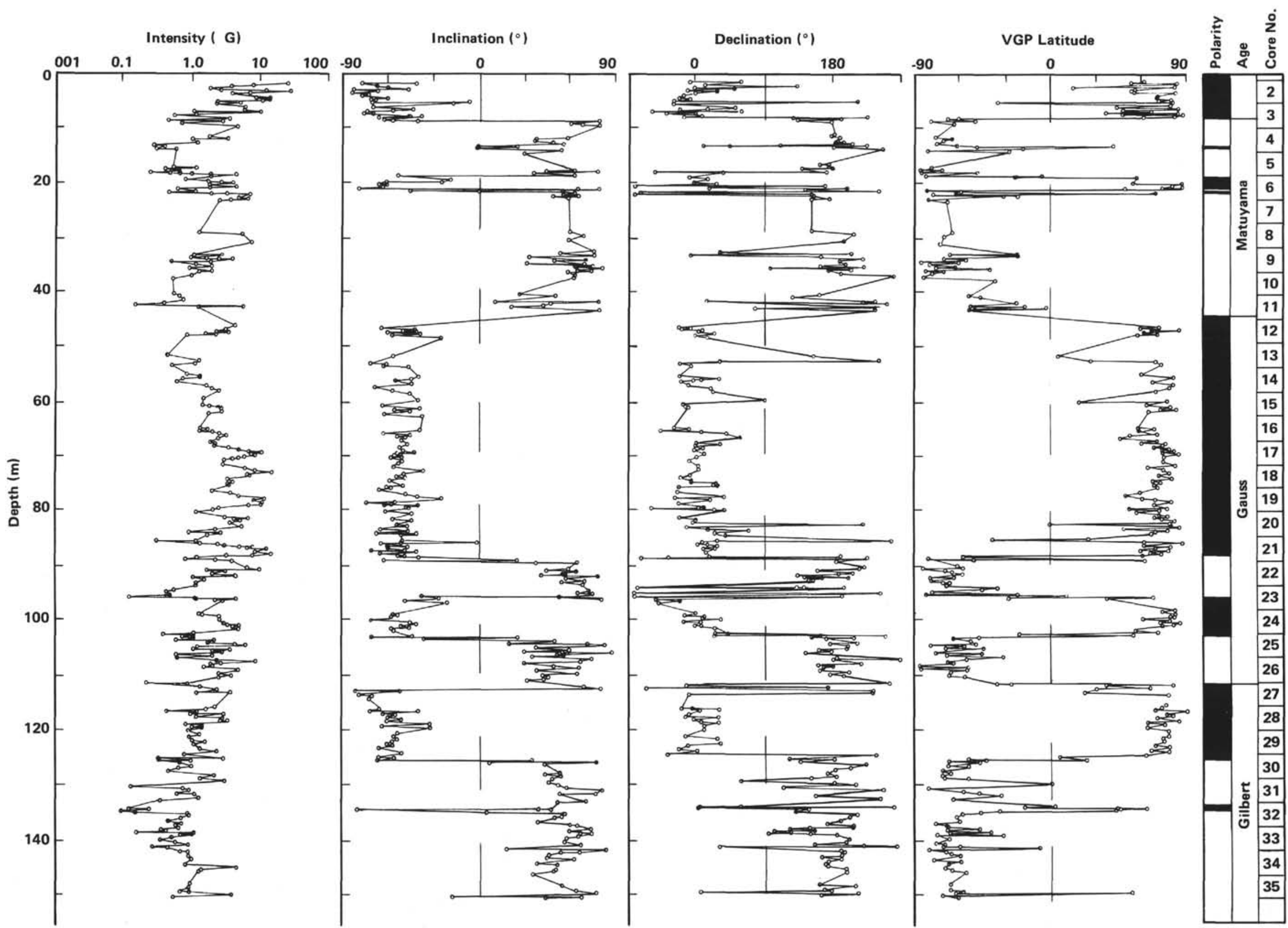




\section{J. C. SALLOWAY}
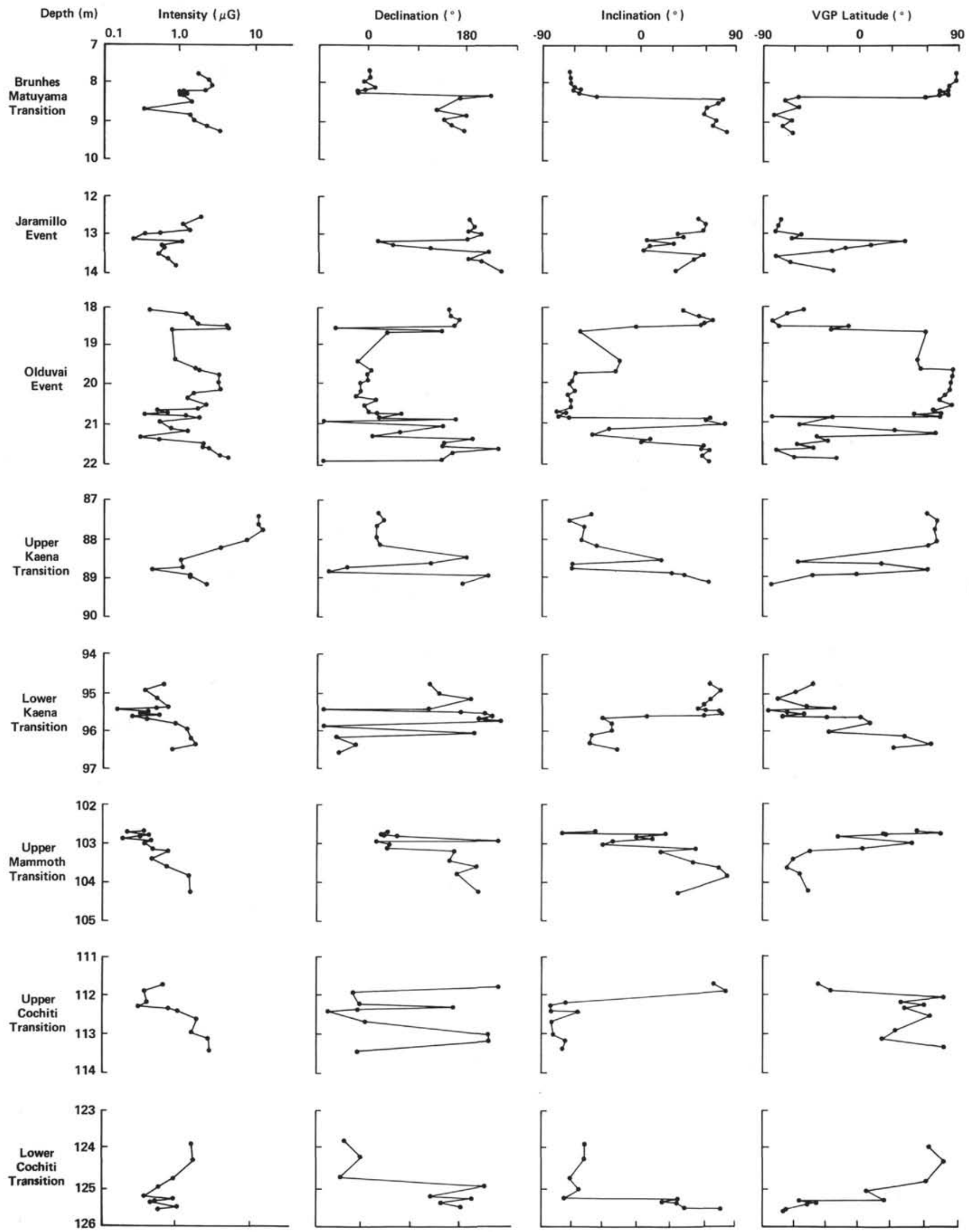

Figure 16. Detailed records of intensity, inclination, declination, and VGP latitude across polarity transitions at Site 514. 
Table 1. VGP positions for transitions shown in Figure 17 .

\begin{tabular}{|c|c|c|c|}
\hline Transition & $\begin{array}{l}\text { Depth } \\
\text { (m) }\end{array}$ & VGP & Position \\
\hline Brunhes-Matuyama & $\begin{array}{l}8.24 \\
8.27 \\
8.29 \\
8.43\end{array}$ & $\begin{array}{l}73.3 \mathrm{~N} \\
61.1 \mathrm{~N} \\
57.6 \mathrm{~S} \\
70.3 \mathrm{~S}\end{array}$ & $\begin{array}{c}78.8 \mathrm{~W} \\
64.4 \mathrm{~W} \\
58.0 \mathrm{~W} \\
3.0 \mathrm{~W}\end{array}$ \\
\hline Jaramillo Event & $\begin{array}{l}13.06 \\
13.16 \\
13.24 \\
13.32 \\
13.42 \\
13.55\end{array}$ & $\begin{array}{l}63.5 \mathrm{~S} \\
43.3 \mathrm{~N} \\
17.3 \mathrm{~N} \\
14.2 \mathrm{~S} \\
26.0 \mathrm{~S} \\
80.6 \mathrm{~S}\end{array}$ & $\begin{array}{r}152.6 \mathrm{E}^{\mathrm{a}} \\
8.6 \mathrm{~W} \\
19.0 \mathrm{E} \\
78.0 \mathrm{E} \\
150.0 \mathrm{~W} \\
154.7 \mathrm{E}\end{array}$ \\
\hline Upper Olduvai & $\begin{array}{l}18.52 \\
18.55 \\
18.58 \\
18.69\end{array}$ & $\begin{array}{r}77.3 \mathrm{~S} \\
8.0 \mathrm{~S} \\
29.9 \mathrm{~S} \\
60.5 \mathrm{~N}\end{array}$ & $\begin{array}{r}94.0 \mathrm{E} \\
70.7 \mathrm{~W} \\
106.6 \mathrm{E} \\
57.9 \mathrm{E}\end{array}$ \\
\hline Lower Olduvai & $\begin{array}{l}20.87 \\
20.90 \\
20.93 \\
21.06 \\
21.22 \\
21.34 \\
21.40 \\
21.49 \\
21.60\end{array}$ & $\begin{array}{l}77.4 \mathrm{~N} \\
85.4 \mathrm{~S} \\
23.8 \mathrm{~S} \\
62.2 \mathrm{~S} \\
29.9 \mathrm{~S} \\
70.0 \mathrm{~N} \\
42.1 \mathrm{~S} \\
32.4 \mathrm{~S} \\
59.3 \mathrm{~S}\end{array}$ & $\begin{array}{r}84.9 \mathrm{E} \\
68.8 \mathrm{E} \\
84.1 \mathrm{~W} \\
1.9 \mathrm{~W} \\
55.6 \mathrm{E} \\
2.7 \mathrm{E} \\
170.7 \mathrm{~W} \\
107.5 \mathrm{E} \\
67.6 \mathrm{E}\end{array}$ \\
\hline Upper Kaena & $\begin{array}{l}88.20 \\
88.55 \\
88.69 \\
88.78 \\
88.90 \\
88.93 \\
89.15\end{array}$ & $\begin{array}{r}61.3 \mathrm{~N} \\
58.0 \mathrm{~S} \\
17.9 \mathrm{~N} \\
62.5 \mathrm{~N} \\
3.7 \mathrm{~S} \\
50.1 \mathrm{~S} \\
82.9 \mathrm{~S}\end{array}$ & $\begin{array}{r}14.1 \mathrm{E} \\
165.9 \mathrm{E}^{\mathrm{a}} \\
110.3 \mathrm{E} \\
124.8 \mathrm{~W} \\
95.5 \mathrm{~W} \\
131.2 \mathrm{~W} \\
21.9 \mathrm{E}\end{array}$ \\
\hline Lower Kaena & $\begin{array}{l}95.59 \\
95.62 \\
95.65 \\
95.80 \\
95.97 \\
96.15 \\
96.34\end{array}$ & $\begin{array}{r}73.4 \mathrm{~S} \\
32.9 \mathrm{~S} \\
2.1 \mathrm{~N} \\
11.1 \mathrm{~N} \\
29.3 \mathrm{~S} \\
39.0 \mathrm{~N} \\
67.6 \mathrm{~N}\end{array}$ & $\begin{array}{c}104.0 \mathrm{~W} \\
157.4 \mathrm{~W} \\
144.5 \mathrm{~W} \\
124.1 \mathrm{~W} \\
170.9 \mathrm{E} \\
116.7 \mathrm{~W} \\
78.4 \mathrm{~W}\end{array}$ \\
\hline Upper Mammoth & $\begin{array}{l}102.75 \\
102.77 \\
102.81 \\
102.86 \\
102.96 \\
103.04 \\
103.13 \\
103.19 \\
103.43\end{array}$ & $\begin{array}{r}72.2 \mathrm{~N} \\
24.5 \mathrm{~N} \\
25.2 \mathrm{~N} \\
20.8 \mathrm{~S} \\
53.8 \mathrm{~N} \\
46.4 \mathrm{~N} \\
3.9 \mathrm{~N} \\
49.5 \mathrm{~S} \\
62.2 \mathrm{~S}\end{array}$ & $\begin{array}{rl}109.2 & \mathrm{E} \\
6.4 & \mathrm{E} \\
38.3 & \mathrm{E} \\
130.1 & \mathrm{~W}^{\mathrm{a}} \\
3.5 & \mathrm{E} \\
39.1 & \mathrm{E} \\
7.3 \mathrm{E} \\
124.2 \mathrm{E} \\
86.3 \mathrm{E}\end{array}$ \\
\hline Upper Cochiti & $\begin{array}{l}111.75 \\
111.92 \\
112.21 \\
112.26 \\
112.36\end{array}$ & $\begin{array}{l}40.6 \mathrm{~S} \\
29.9 \mathrm{~S} \\
78.5 \mathrm{~N} \\
33.2 \mathrm{~N} \\
59.9 \mathrm{~N}\end{array}$ & $\begin{array}{c}83.5 \mathrm{~W} \\
34.9 \mathrm{~W}^{\mathrm{a}} \\
153.5 \mathrm{~W} \\
151.1 \mathrm{E} \\
158.7 \mathrm{E}\end{array}$ \\
\hline Lower Cochiti & $\begin{array}{l}124.76 \\
125.03 \\
125.28 \\
125.32 \\
125.36 \\
125.38 \\
125.51\end{array}$ & $\begin{array}{r}59.3 \mathrm{~N} \\
3.1 \mathrm{~N} \\
21.5 \mathrm{~N} \\
56.9 \mathrm{~S} \\
41.9 \mathrm{~S} \\
50.2 \mathrm{~S} \\
67.0 \mathrm{~S}\end{array}$ & $\begin{array}{c}139.8 \mathrm{~W} \\
167.5 \mathrm{~W} \\
118.1 \mathrm{E} \\
161.9 \mathrm{~W} \\
99.9 \mathrm{E} \\
93.9 \mathrm{E} \\
165.0 \mathrm{E}\end{array}$ \\
\hline
\end{tabular}

a Samples with irregular demagnetization paths. tle agreement with previous results for similar transitions, which suggests that the geomagnetic field is not dipolar during the transition. The paths for the Jaramillo are markedly different from those reported by Hammond et al. (1979) and Opdyke et al. (1973). The path for the upper Olduvai transition differs by about $45^{\circ}$ from that of Hammond et al. and by $90^{\circ}$ from that of Opdyke et al.

Intensity ranges from 0.1 to $30.0 \mu \mathrm{G}$ throughout the hole. Large-scale variation is similar to that shown by susceptibility, indicating that intensity variation is controlled largely by magnetic mineralogy (see Bloemendal, this volume, for a full discussion). Intensity change during the reversals is included in Figure 16. In most cases there is a low in intensity coincident with the transition, which is not matched by a low in susceptibility (e.g., the Jaramillo and Kaena events). A low intensity occurs shortly before the Brunhes/Matuyama boundary whereas the upper Olduvai transition is characterized by a high intensity. The variations in intensity at the reversals are of the same order as variations in other parts of the section (e.g., Core 11 between depths of $40 \mathrm{~m}$ and 43 $\mathrm{m}$-see Fig. 15). There does, however, appear to be some support for low intensities during a reversal.

Using sedimentation rate calculated from magnetic boundaries (after Mankinen and Dalrymple, 1979) and diatom zone boundaries (see site chapter), it is possible to work out the time taken for a reversal of the geomagnetic field. The period of transitions is defined as the length of time between samples having a VGP latitude of $55^{\circ}$ or greater on either side of the reversal. $55^{\circ}$ is the limit of variation of the VGP latitude during "quiet" magnetic intervals. As sampling was not continuous, the reversal times will be overestimated. As already noted, the Brunhes/Matuyama boundary occurred abruptly, the two samples defining the limits of the transition separated by just over 1000 years. The Jaramillo and Olduvai events are recorded in sediments with low rates of accumulation, so that gaps in sampling will give rise to large errors. The Jaramillo Event is also complicated by the possible occurrence of an unconformity. Estimated times for the four transitions range from 11,000 to 80,000 years. Sedimentation rate was much higher preceding the Olduvai Event, so it is felt that estimates for the remaining five transitions are more accurate. Reversal lengths range from 3000 to 10,000 years. Considering the large error involved, the average of 6500 years agrees favorably with the 4600 years quoted by Opdyke et al. (1973).

There is large variation in the style of transition: some appear sharp-for example, the Brunhes/Matuyama boundary; others involve longitudinal drift of the VGP position-e.g., the lower Jaramillo transition; and some are composed of several short reversals-e.g., the lower Olduvai transition. Intermediate pole positions do not show any preferred orientation and show little agreement with previously reported paths for the same reversals. These factors suggest that the geomagnetic field is mainly nondipolar during polarity transitions. 


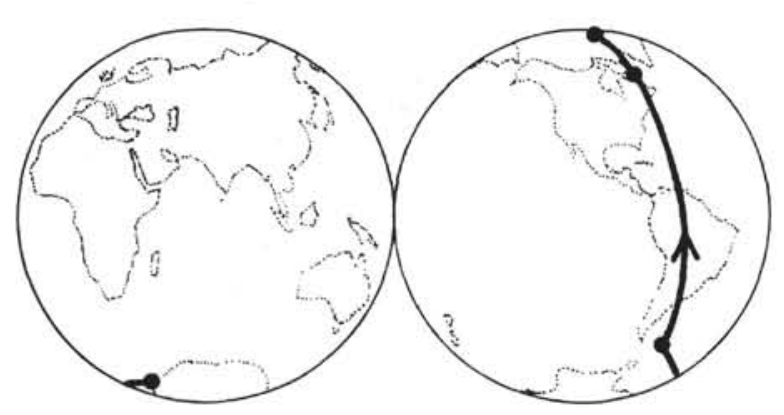

Brunhes Matuyama Transition

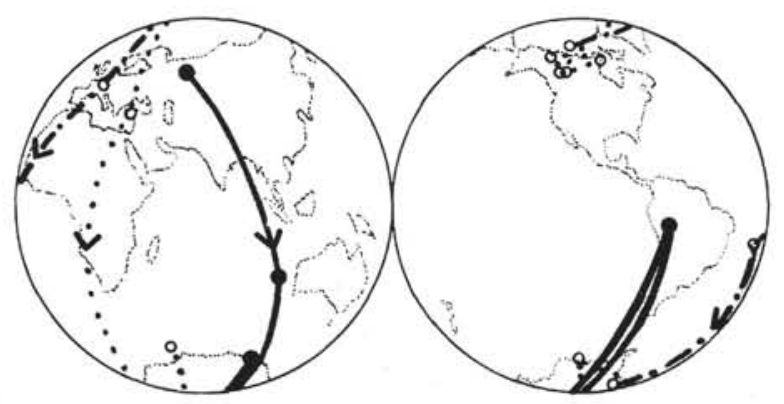

Upper Olduvai Transition

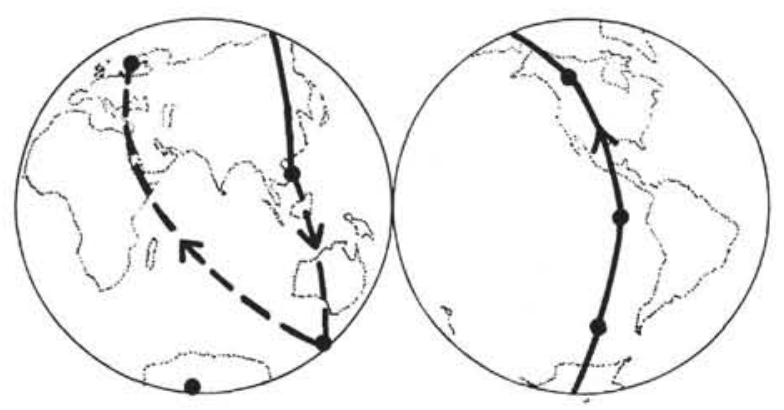

Upper Kaena Transition

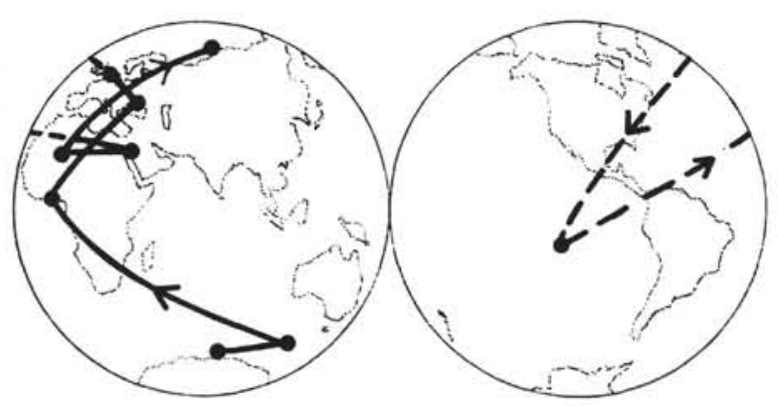

Upper Mammoth Transition

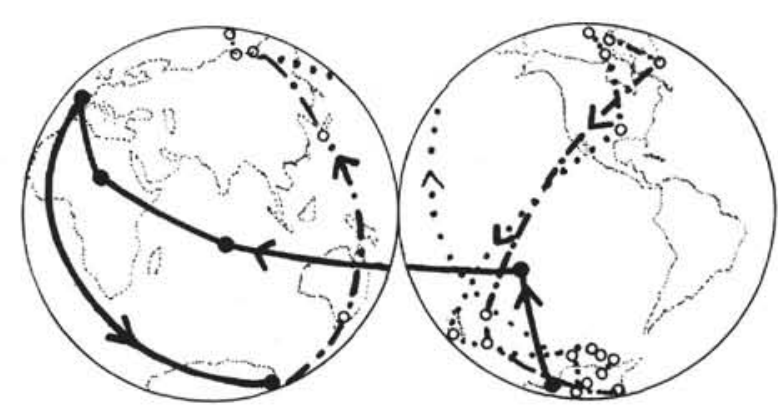

Jaramillo Event

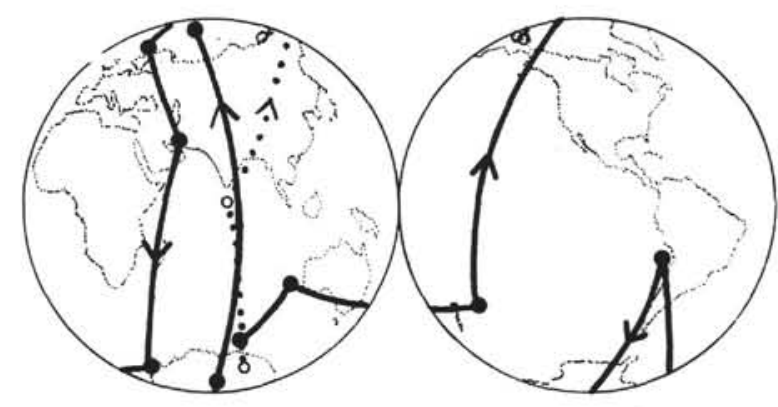

Lower Olduvai Transition

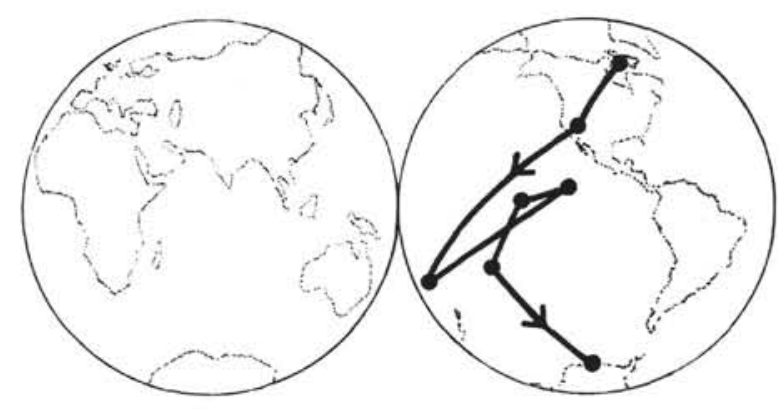

Lower Kaena Transition

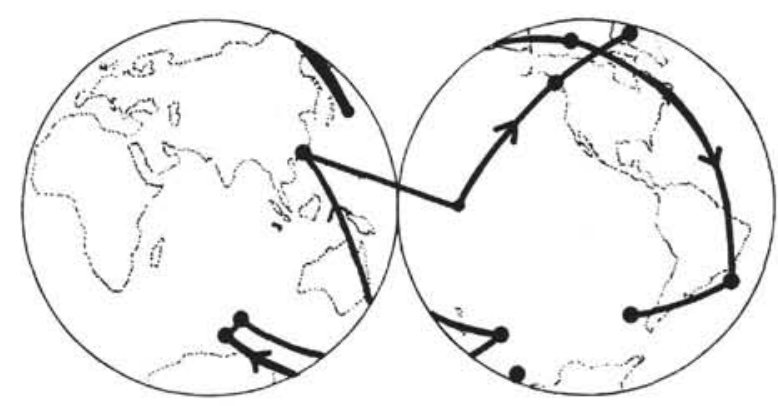

Cochiti Event

Site 514

- Hammond et al. (1979)

Opdyke et al. (1973)

Figure 17. Virtual geomagnetic pole positions for the polarity transitions recorded at Site 514. Broken lines indicate VGP positions calculated from samples which display irregular demagnetization paths. VGP paths from Hammond et al. (1979) and Opdyke et al. (1973) are also shown. 


\section{CONCLUSIONS}

Paleomagnetic investigations of deep sea sediments show that an accurate record of the geomagnetic field is preserved, permitting interpretation of polarity intervals and development of a magnetostratigraphy, given a complete sedimentary record. At Site 511 a record of Cretaceous polarity was obtained which shows agreement with previously obtained magnetostratigraphies. At Site 513 a fairly complete upper Miocene magnetostratigraphy is preserved, permitting comparison with biostratigraphy. The magnetic record at Site 514 is very good, allowing clear correlation of magnetostratigraphy with biostratigraphy back to the upper Gilbert Epoch. Inclination errors are present, as noted in deposits with high sedimentation rates (see summary, Verosub, 1977).

Small secondary magnetizations may be present in the sediment or may develop owing to drilling or to postcruise transportation. These disappear with demagnetization at low fields or if allowed to relax through storage in a reduced field. This shows that secondary magnetization is of a viscous nature.

The quality of the material retrieved by hydraulic piston coring is superior to that obtained by conventional rotary coring. This improvement is particularly important for paleomagnetic work, where undisturbed sediment is essential. Although relative orientation of cores was not recorded, it was possible to use declination for paleomagnetic interpretation, as no relative movement occurred within cores.

High sedimentation rates at Site 514 have allowed the study of polarity transitions. A variety of styles of transition is observed, with longitudinal drift of virtual geomagnetic pole positions in some cases. The difference in paths between this work and others for the same reversal, and the meandering of VGP positions, suggests that the nondipole field is dominant during reversals.

\section{ACKNOWLEDGMENTS}

I would like to thank E. A. Hailwood and C. E. Barton for reviewing this article. The work was carried out while I was receiving an
N.E.R.C. Studentship. J. Bloemendal carried out some of the shipboard measurements.

\section{REFERENCES}

Green, K. E., and Brecher, A., 1974. Preliminary paleomagnetic results for sediments from Site 263, Leg 27. In Veevers, J. J., Heirtzler, J. R., et al., Init. Repts. DSDP, 27: Washington (U.S. Govt. Printing Office), 405-413.

Hailwood, E. A., 1979. Paleomagnetism of Late Mesozoic to Holocene sediments from the Bay of Biscay and Rockall Plateau, drilled on IPOD Leg 48. In Montadert, L., Roberts, D. G., et al., Init. Repts. DSDP, 48: Washington (U.S. Govt. Printing Office) 305-339.

Hammond, S. R., Seyb, S. M., and Theyer, F., 1979. Geomagnetic polarity transitions in two oriented sediment cores from the northwest Pacific. Earth Planet. Sci. Lett., 44:167-175.

Keating, B. H., Helsley, C. E., and Pessagno, E. A., 1975. Late Cretaceous reversal sequence. Geology, 3:73-76.

LaBrecque, J. L., Kent, D. V., and Cande, S. C., 1977. Revised magnetic polarity time scale for Late Cretaceous and Cenozoic time. Geology, 5:330-335.

Larson, R. L., and Hilde, T. W. C., 1975. A revised time scale of magnetic reversals for the Early Cretaceous and Late Jurassic. J. Geophys. Res., 80:2586-2594.

McElhinny, M. W., 1973. Palaeomagnetism and Plate Tectonics: Cambridge, U.K. (Cambridge University Press).

Mankinen, E. A., and Dalrymple, G. B., 1979. Revised geomagnetic polarity time scale for the interval 0-5 m.y. B.P.. J. Geophys. Res., $84: 615-626$.

Opdyke, N. D., Kent, D. V., and Lawrie, W., 1973. Details of magnetic polarity transitions recorded in a high deposition rate deep sea core. Earth Planet. Sci. Lett., 20:315-324.

Smith, A. G., and Briden, J. C., 1977. Mesozoic and Cenozoic Palaeocontinental Maps: Cambridge, (Cambridge University Press).

Stephenson, A, 1980a. Rotational remanent magnetisation and the torque exerted on a rotating rock in an alternating magnetic field. Geophys. J.R. Astron. Soc., 62:113-132.

1980b. A gyroremanent magnetisation in anisotropic magnetic material. Nature, 284:49-51.

Van Hinte, J. E., 1976. A Cretaceous time scale. Am. Assoc. Pet. Geol. Bull., 60:498-516.

Verosub, K. L., 1977. Depositional and postdepositional processes in the magnetisation of sediments. Rev. Geophys. Space Phys., 15: 129-143.

Wilson, R. L., and Lomax, R. 1972. Magnetic remanence related to slow rotation of ferromagnetic material in alternating magnetic fields. Geophys. J.R. Astron. Soc., 30:295-303. 